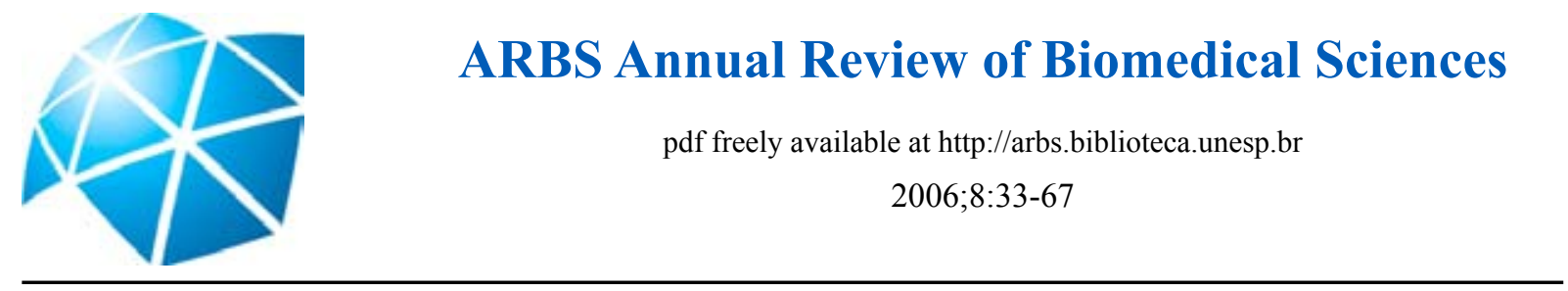

\title{
Aging Changes of Macromolecular Synthesis in the Avian and Mammalian Eyes as Revealed by Microscopic Radioautography
}

\author{
Tetsuji Nagata ${ }^{1}$ \\ Department of Anatomy and Cell Biology, Shinshu University and Shinshu Institute of Alternative \\ Medicine, Japan
}

Received: 02 October 2006; accepted 01 November 2006

\begin{abstract}
Nagata T. Aging Changes of Macromolecular Synthesis in the Avian and Mammalian Eyes as Revealed by Microscopic Radioautography. ARBS Annu Rev Biomed Sci 2006;8:33-67. In order to elucidate the aging changes of macromolecular synthesis such as DNA, RNA, proteins and glucides in various organ systems of experimental animals and men, we have studied various organs such as the skeletal, muscular, digestive, respiratory, urinary, reproductive, endocrine, circulatory, nervous and sensory systems after incorporations with radiolabeled macromolecular precursors by light and electron microscopic radioautography. This review deals with the results obtained from the avian and mammalian eyeballs. The experimental animals mainly used were chicken embryos during incubation for 1-7 days and strain mice at various aging groups from embryo to postnatal juvenile 1 and 3 days, 1 and 2 weeks, mature 1, 2 and 6 months up to 1 and 2 years at senescent stages. The animals were injected with such macromolecular precursors as ${ }^{3} \mathrm{H}$-thymidine for DNA, ${ }^{3} \mathrm{H}$-uridine for RNA, ${ }^{3} \mathrm{H}$-amino acids for proteins, ${ }^{3} \mathrm{H}$-glucose, ${ }^{3} \mathrm{H}$-glucosamine and ${ }^{35} \mathrm{~S}$-sulfate for glucides. The results demonstrated that these precursors were incorporated into various ocular cells and tissues at various aging groups from perinatal to juvenile, mature and senescent stages showing specific patterns of macromolecular synthesis. It is concluded that the difference of macromolecular syntheses during development and aging changes were demonstrated.

(C) by São Paulo State University - ISSN 1806-8774
\end{abstract}

Keywords: radioautography, DNA, RNA, proteins, glucides synthesis, aging, mouse, chicken

\section{${ }^{1}$ Correspondence}

Dept. of Anatomy and Cell Biology, Shinshu University School of Medicine, Matsumto 390-8621, Japan, and Dept. of Anatomy, Shinshu Institute of Alternative Medicine, Nagano 380-0816, Japan. E-mail: nagatas@po.cnet.ne.jp 


\section{Table of Contents}

1. Introduction

2. Methodology

2.1. Radioisotopes and Radiolabeled Compounds

2.2. Animals

2.2.1. Avian Embryos

2.2.2. Mammals

2.2.3. Animal Treatment and Tissue Processing

2.2.4. Fixation of Tissues and Cells

2.2.4.1. Chemical Fixation for Insoluble Compounds

2.2.4.2. Cryo-fixation for Soluble Compounds

2.3. Techniques of Radioautography

2.3.1. Light Microscopic Radioautography

2.3.2. Electron Microscopic Radioautography

3. Application of Radioautography to the Eye

3.1. The External Layer of the Eyeball (Tunica fibrosa)

3.1.1. The Sclera

3.1.2. The Cornea

3.2. The Middle Layer of the Eyeball (Tunica media,Vascular Layer or Uvea)

3.2.1. The Choroid

3.2.2. The Ciliary Body

3.2.3. The Iris

3.3. The Inner Layer of the Eyeball (Tunica interna or retina)

3.3.1. The Pigment epithelium

3.3.2. The Retina proper

3.4. The Refractive Components of the eyeball

4. Concluding Remarks

5. Acknowledgments

6. References

\section{Introduction}

For the purpose of estimating aging changes of various organs of experimental animals and men, various kinds of methodologies are now available including morphological, physiological and biochemical procedures. Among of them, one of the good methods to demonstrate the sites of incorporations, syntheses and discharge of various substances in animals should be microscopic radioautography. We have developed new techniques for both light and electron microscopic radioautography to localize intracellular sites of metabolism at cell organelle level by fixing tissues with chemical fixatives followed by conventional wet-mounting radioautography as well as to demonstrate soluble compounds by fixing tissues with cryo-fixation followed by dry-mounting radioautography in our laboratory during these 50 years (Nagata, 1962, 1966, 1967, 1972, 1982, 1991, 1992, 1993a,b, 1994a,b,c, 1995a, 1996a,b,c, 1997a, 1998a,b, 1999a, 2001a, 2002a, 2004). The localization of silver grains developed by means of ordinary radioautography demonstrates only the insoluble radioactive substances bound to the macromolecules fixed in the cell with the chemical fixatives used, while the radioisotopes bound to the small molecules which are not fixed with ordinary fixatives can be demonstrated by only cryo-fixation and dry-mounting radioautography (Nagata, 1972, 1992, 1994a,b,c, 1996a, 2002a, 2004). Ordinary radioautographic procedures can be designated as wet-mounting radioautography, since the tissues are processed through both conventional wet treatments and applying wet radioautographic emulsions to the specimens. In order to demonstrate any soluble radioactive compounds, special techniques are required in accordance with the characteristics of the radioisotopes used for radioautography by dry-mounting procedures (Nagata \& Nawa, 1966; Nagata \& Murata, 1977; Nagata et al., 1969; Nagata, 1994a).

We have developed novel techniques to demonstrate both soluble and insoluble radiolabeled compounds in cells and tissues at light and electron microscopic levels and then applied these methodologies to various organ systems of experimental animals during aging, from embryo to postnatal juvenile, mature and senescent stages, using radiolabeled precursors for macromolecular synthesis and established a new science designated as radioautographology (Nagata, 1998b, 2002a). The results obtained from several organ systems in our laboratory have been reviewed in detail such as the respiratory organs (Nagata, 2001b), digestive organs (2002b) and urogenital organs (Nagata, 2005), respectively. This paper reviews the results obtained from the optic organ, especially the eyes of avian and mammalian experimental animals, during these 30 years in our laboratory. 


\section{Methodology}

We used radioautography which is a technique to demonstrate the patterns of localization of radioactive substances in various specimens incorporating radioactive compounds (Nagata, 1992, 1994c, 2002a). The radioautograms can be observed by either naked eyes or light and electron microscopy. The specimen which consists of tissues and cells in contact with the photographic emulsion containing developed silver grains is called radioautograph, while the pattern of silver grains on the radioautograph is called radioautogram and the procedure to produce radioautographs is designated as radioautography. Radioautograph is the autograph produced by radiation. Autograph is a positive picture made by itself. Therefore, the term radioautogram means etymologically the positive picture produced by radiation which is emitted from the object itself resulting in autogram. To the contrary, autoradiograph consists of auto and radiograph. The suffix auto means automatic, while the term radiograph means the picture of the object which is penetrated by rays resulting in negative images such as chest X-ray films. Thus, autoradiograph etymologically means a negative picture of the specimen produced automatically with radiation emitted from another radiation source away from the specimens which is quiet different from radioautographs (Nagata, 1992, 1994b,c, 2002a). However, it is now generally accepted that the both terms, radioautography and autoradiography, are considered to be the synonyms. On the other hand, we had advocated a new concept, named "radioautographology." This new term is the coinage synthesized from radioautography and ology, expressing a new science derived from radioautography. The concept of radioautographology is a science to localize the radioactive substances in the structure of the objects and to analyze and to study the significance of these substances in the structure (Nagata, 1996b, 1998b, 2002a). The science, radioautographology, can be divided into 2 parts, general radioautographology and special radioautographology. The former deals with the principle and techniques of radioautography, while the latter deals with the application of radioautography to various materials (Nagata, 1998b, 2002a). General radioautographology is the technology including all the natural sciences to produce the specimens, which contain radioactive compounds, procedures for tissue preparations and the methods to make tissues contact with the photographic emulsions and to give exposure for a certain period of time to produce the latent images of the radioactive substances in the specimens, then to develop the emulsion to produce the silver metal grains, thus enabling to compare both the specimens and radioautograms in order to learn the localization of radioactive substances in the specimens. We developed the technologies for light (LM) and electron microscopic (EM) radioautography (RAG) and applied them to cell biology and cytochemistry (Nagata, 1996a,b,c, 1997a, 1998a,b, 2001a, 2002a). The radioactive compounds used in radioautography are mainly composed of inorganic or organic compounds which are artificially labeled with radioisotopes (RI) and can be incorporated into human or animal bodies by experiments. The radioactivity emitted from the radioactive isotopes is divided into three kinds of rays, i.e., alpha, beta and gamma rays. Among these three rays, the beta ray is the best for radioautography because of its shorter range and the strongest ionization. For radioautography various kinds of RIs are used. Among them, ${ }^{3} \mathrm{H},{ }^{14} \mathrm{C},{ }^{35} \mathrm{~S}$ and ${ }^{125} \mathrm{I}$ are very often utilized because they can be labeled to various inorganic compounds which are usually used in biomedical researches. The RI-labeled compounds used for radioautography can be classified into two categories, i. e., the precursors which are incorporated into macromolecules such as nucleic acids (DNA and RNA), proteins, glucides and lipids, and the other target tracers which are small molecular compounds such as hormones, neurotransmitters, vitamins, inorganic substances, drugs and others. The macromolecular synthesis is labeled with ${ }^{3} \mathrm{H}$-thymidine (for DNA), ${ }^{3} \mathrm{H}$-uridine (for RNA) amino acids such as ${ }^{3} \mathrm{H}$-glycine or ${ }^{3} \mathrm{H}$-leucine (for proteins), ${ }^{3} \mathrm{H}$-glucose, ${ }^{3} \mathrm{H}$-glucosamine or ${ }^{35} \mathrm{SO}_{4}$ (for glucides) and ${ }^{3} \mathrm{H}$-glycerol or ${ }^{3} \mathrm{H}$-fatty acids (for lipids). The experimental animals mainly used in these experiments were ddY strain mice which were maintained and bred in our laboratory and white Leghorn chick embryos incubated in our laboratory. In order to localize the sites of incorporation of radioactive compounds in animal bodies, the compounds which were labeled with specific RIs were usually administered by injections given subcutaneously, intramuscularly, intravenously or intraperitoneally. In these experiments, we injected the animals intraperitoneally with radioactive precursors for macromolecular syntheses at varying concentrations such as $37-1850 \mathrm{KBq}(1-50 \mu \mathrm{Ci}) /$ gram body weight for both LMRAG and EMRAG or $370-3700 \mathrm{KBq}(10-100 \mu \mathrm{Ci}) / \mathrm{g} . \mathrm{b} . \mathrm{w}$. depending on the characteristics of the compounds and RIs used. Embedded tissues in epoxy resin can be used for either light or electron microscopy. For light microscopy thick sections at $2 \mu \mathrm{m}$ were cut on an LKB ultramicrotome or a Porter-Blum MT-2B ultramicrotome using glass knives, while ultrathin sections at $100 \mathrm{~nm}$ thickness were cut for conventional 
transmission electron microscope with the accelerating voltage at $100 \mathrm{kV}$. It is generally accepted that the thinner the section is the better the resolution, but the less the radioactivity it contains and the longer the exposure time for radioautography. We prefer to use semithin sections at $200 \mathrm{~nm}$ thickness by observing with high voltage electron microscopy at $400 \mathrm{kV}$ in order to shorten the exposure time (Nagata, 1998a, 2002a). We have developed simple routine standard techniques to demonstrate both soluble and insoluble compounds in various cells and tissues of experimental animals and to quantify the contents of synthesized macromolecules in each cell and cell organelle by both light and electron microscopy. The techniques for microscopic radioautography developed in our laboratory can be divided into two categories, i.e., wet-mounting radioautography for insoluble compounds, such as macromolecular synthesis, and drymounting radioautography for soluble compounds, such small molecular compounds as drugs using cryo-techniques including cryo-fixation, cryo-sectioning, freeze-drying and freeze-substitution (Nagata, 1992, 1994a, 1996b, 1998a, 2002a).

\subsection{Radioisotopes and radiolabeled compounds}

Many radioactive isotopes (RI) are now commercially available in any countries. Among them, ${ }^{3} \mathrm{H},{ }^{14} \mathrm{C},{ }^{35} \mathrm{~S}$ and ${ }^{125} \mathrm{I}$ were utilized for both light and electron microscopic radioautography because they can be labeled to various inorganic compounds which are usually used in biomedical researches. The radioactive compounds used in radioautography in our experiment are composed of inorganic or organic compounds which are artificially labeled with radioisotopes (RI) and can be incorporated into animal bodies by experiments. The RI-labeled compounds used for radioautography can be classified into 2 categories, i.e., the precursors which are incorporated into macromolecules such as nucleic acids (DNA and RNA), proteins, glucides and lipids, and the other target tracers which are small molecular compounds such as hormones, neurotransmitters, vitamins, and inorganic substances.

For the purpose of localizing sites of incorporation of radioactive compounds in animal bodies, the compounds which were labeled with specific RIs were usually administered by injections given subcutaneously, intramuscularly, intravenously or intraperitoneally, or otherwise ocular tissues were taken out from animals and incubated in vitro in media containing RI-labeled compounds under experimental conditions. We have usually injected the animals intraperitoneally with radioactive precursors for macromolecular syntheses at varying concentrations as $37-1850 \mathrm{KBq}(1-50 \mu \mathrm{Ci}) /$ gram body weight for both LMRAG and EMRAG or 370-3700 KBq (10-100 $\mu \mathrm{Ci}) /$ g.b.w. depending on the characteristics of the compounds and RIs used. The RI-labeled precursors used in these experiments were ${ }^{3} \mathrm{H}$-thymidine (Amersham, England, UK, specific activity $877 \mathrm{GBq} / \mathrm{mM}$ ) for DNA synthesis, ${ }^{3} \mathrm{H}$-uridine (Amersham, England, $1.11 \mathrm{TBq} / \mathrm{mM}$ ) for RNA synthesis, d-4,5- ${ }^{3} \mathrm{H}$-leucine (Amersham, England, UK, specific activity $1.04 \mathrm{TBq} / \mathrm{mM}$ ) or d- ${ }^{3} \mathrm{H}$-proline (Amersham, England, UK, specific activity $877 \mathrm{GBq} / \mathrm{mM}$ ) for proteins, ${ }^{35} \mathrm{~S}$-sulfuric acid (Amersham, England, UK, specific activity $1.11 \mathrm{TBq} / \mathrm{mM}$ ) for mucosubstances, and d-1,6- ${ }^{3} \mathrm{H}$-glucosamine (New England Nuclear Corporation, Boston, MA, USA, specific activity 185 $\mathrm{MBq} / \mathrm{mM}$ ) for glucides (Nagata, 1992, 1994c, 1997a, 2001a, 2002a).

\subsection{Animals}

As experimental animals we mainly used both chick embryos in incubation as well as prenatal and postnatal developing ddY mice at various ages which were maintained and bred in our laboratory.

\subsubsection{Avian embryos}

One hundred fertilized white Leghorn eggs were purchased from a local hatchery (Komatsu Hatchery, Matsumoto, Japan) and were incubated in moist incubators at $38.5^{\circ} \mathrm{C}$ for several days on our laboratory. The eggs were observed everyday and around 20 chicken embryos were taken out on 2, 3, 4 and 7 days at embryonic stages from 9-12, 14-20, 23-24, and 31-32 stages of Hamburger and Hamilton (1951), respectively. The ocular tissues were taken out, dissected in Hanks' balanced salt solution (Nissui, Tokyo, Japan) and then the tissues were cultured in vitro in Eagle's MEM (Nissui, Tokyo, Japan) supplemented with $10 \%$ calf serum (Nissui, Tokyo, Japan) containing either ${ }^{3} \mathrm{H}$-thymidine or ${ }^{3} \mathrm{H}$-uridine in a $\mathrm{CO}_{2}$ incubator at $37^{\circ} \mathrm{C}, 5 \% \mathrm{CO}_{2}$ in air, $90 \%$ relative humidity and $\mathrm{pH} 7.5+0.1$, for 1,2 and $4 \mathrm{~h}$. 


\subsubsection{Mammals}

Two hundreds and thirty-one ddY strain mice of both sexes in 11 aging groups each consisting of 3 litter animals respectively, from fetal day 16 and 18, postnatal 1 and 3 days, 1 and 2 weeks, 1, 2, 6 months, were used for this experiment. They were bred in our laboratory and were housed under conventional conditions, fed with normal mice chow (Clea CE2, Tokyo, Japan) with access to water ad libitum. The embryonic age was based on observation of the vaginal plug of the female mice (vaginal plug = day 0 ). They were sacrificed at given time with pentobarbital sodium (Nembutal, Abbott Laboratories, Chicago, IL, USA) anesthesia and perfusing via the left ventricles of the hearts with $2.5 \%$ glutaraldehyde in $0.1 \mathrm{M}$ cacodylate buffer ( $\mathrm{pH}$ 7.2) one hour after injections with radiolabeled compounds for radioautography. Some other animals such as postnatal Wistar rats or some adult albino rabbits in several groups were occasionally used for specific experiments such as drug instillations which will be described below.

\subsubsection{Animal treatment and tissue processing}

All the experimental animals such as mice and rats, except chicken embryos, were anesthetized by intraperitoneal injections with pentobarbital sodium (Nembutal, Abbott Laboratories, Chicago, Ill., USA), after administrations of radioactive compounds by intraperitoneal injections, and are sacrificed at given time, usually $1 \mathrm{~h}$ after the RI administration by perfusing via the left ventricles of the hearts with $2.5 \%$ glutaraldehyde in $0.1 \mathrm{M}$ cacodylate buffer at $\mathrm{pH} 7.2$, depending on whether insoluble or soluble radioautography will be carried out. For conventional insoluble radioautography the perfusion fixation can be used and the tissues from various organs were taken out, cut into small pieces $(1 \times 1 \times 1 \mathrm{~mm})$, soaked in the same glutaraldehyde fixative at $4{ }^{\circ} \mathrm{C}$ for $1 \mathrm{~h}$ and postfixed in $1 \%$ osmium tetroxide in the same buffer for $1 \mathrm{~h}$, dehydrated with graded ethanol and embedded in epoxy resin (Epon 812 or Epok 812, Oken Co., Tokyo, Japan). On the other hand, in vitro labeling of cultured cells and tissue blocks obtained from either animals or human biopsy materials were incubated in media containing radioactive compounds, using $\mathrm{CO}_{2}$ incubator under normal conditions at $37^{\circ} \mathrm{C}$ for given time, usually $1 \mathrm{~h}$ or up to a few hours. They were then rinsed in Hanks' solution, fixed in the same buffered glutaraldehyde and osmium tetroxide solutions, dehydrated and embedded in epoxy resin as above.

For the soluble radioautography, however, perfusion fixation can not be used. The whole bodies of the small animals or organs and tissues taken out after decapitation without using any solution, should be immediately cryo-fixed by either metal contact method or immersion method cooled with liquid nitrogen and be processed by cryo-sectioning (Nagata \& Murata, 1977) or freeze-drying or freezesubstitution (Nagata, 1994a). Embedded tissues in epoxy resin can be used for either LMRAG or EMRAG. For LMRAG, thick sections at $2 \mu \mathrm{m}$ are cut on an ultramicrotome and picked up onto clean glass slides and warmed for extension and drying. For electron microscopy, ultrathin sections of $100 \mathrm{~nm}$ thickness are cut in general using a conventional transmission electron microscope with the accelerating voltage at $100 \mathrm{kV}$. It is generally accepted that the thinner the section is the better the resolution, but the less the radioactivity it contains and the longer the exposure time for radioautography. If any intermediate high voltage electron microscope is available at such accelerating voltages as 200,300 or $400 \mathrm{kV}$, thicker sections at 200 or $300 \mathrm{~nm}$ thick can be used. We prefer to use semithin sections at $200 \mathrm{~nm}$ thickness at $400 \mathrm{KV}$ in order to shorten the exposure time (Nagata, 1997b). Semithin sections are cut on a PorterBlum MT-2B ultramicrotome (Dupont-Sorvall, Newtown, CONN, USA). Ultramicrotomes of mechanical feeding type are preferable than thermal feeding type because of the accuracy of the section thickness, which effect on the number of silver grains by radioautography. Ultrathin or semithin sections are picked up onto either platinum or gold meshes in order to prevent the copper meshes from rusting through the histologic and radioautographic treatment especially by the development. Alternatively, collodion coated copper grid meshes can be used.

\subsubsection{Fixation of tissues and cells}

We have developed simple routine standard techniques to demonstrate insoluble compounds in various cells and tissues of experimental animals and to quantify the contents of synthesized macromolecules in each cell and cell organelle by both light and electron microscopy. The localization of silver grains developed by means of ordinary radioautography, however, demonstrates only the insoluble radioactive substances bound to the macromolecules fixed in the cell with the chemical fixatives used (Nagata, 1992, 1996a, 1997a, 1998a, 2002a). On the other hand, radioisotopes bound to the small molecules which are not fixed with ordinary chemical fixatives are washed away through conventional routine 
procedures such as fixation, dehydration, embedding, sectioning, and radioautographic procedures, so that these compounds cannot be demonstrated. Ordinary radioautographic procedures can be designated as wet-mounting radioautography, since the tissues are processed through both conventional wet treatments and applying wet radioautographic emulsions to the specimens. In order to demonstrate any soluble radioactive compounds, special techniques are required in accordance with the characteristics of the radioisotopes used for radioautography. The techniques for microscopic radioautography developed in our laboratory can be divided into 2 categories, i.e., wet-mounting radioautography for insoluble compounds such as macromolecular synthesis and dry-mounting radioautography for soluble compounds such as small molecular compounds, each can be sub-divided into 2 methods, respectively, light microscopy and electron microscopy (Nagata, 1994a,b, 1997a, 1998a, 2002a; Nagata \& Murata, 1977).

\subsubsection{Chemical fixation for insoluble compounds}

Small animals such as mice and rats are anesthetized and sacrificed either by decapitation or by perfusing via the left ventricles of the hearts with $2.5 \%$ glutaraldehyde in $0.1 \mathrm{M}$ cacodylate buffer at $\mathrm{pH} 7.2$ and the tissues from various organs are taken out, cut into small pieces, soaked in the same glutaraldehyde fixative at $4^{\circ} \mathrm{C}$ for $1 \mathrm{~h}$ and postfixed in $1 \%$ osmium tetroxide in the same buffer for 1 $\mathrm{h}$, dehydrated with graded ethanol and embedded in epoxy resin. On the other hand, cultured cells and tissue blocks, incubated in media containing radioactive compounds in vitro, using $\mathrm{CO}_{2}$ incubator under normal conditions at $37^{\circ} \mathrm{C}$ for given times, are rinsed in Hanks' solution, fixed in the same buffered glutaraldehyde and osmium tetroxide solutions, dehydrated and embedded in epoxy resin as above. The tissue blocks are cut on an ultratome for either LM (2 $\mu \mathrm{m}$ thick) or EM $(0.1-2 \mu \mathrm{m})$ and picked up onto either glass slides or grid meshes using water.

\subsubsection{Cryo-fixation for soluble compounds}

By the freezing method, on the other hand, the labeled tissues are quickly frozen in a cooled liquid such as isopentane or propane cooled to its melting point with liquid nitrogen. Then the tissues can be cut by cryo-microtomy. At the light microscopic level, the frozen tissues can be cut in a cryostat and the frozen sections are placed in contact with radioautographic emulsions by various methods. At the light microscopic level, the frozen tissues can be cut in a cryostat at a thickness around 20-30 $\mu \mathrm{m}$ and the frozen sections are placed in contact with radioautographic emulsions by various techniques. Many papers have been published on this problem. We first used a large-wire loop to produce dry films which were air-dried and applied to cryostat sections placed on glass slides (Nagata \& Nawa, 1966a). This procedure is very convenient and often used for demonstrating soluble compounds. At the electron microscopic level, however, only a few papers have been published on this principle, cryo-ultramicrotomy. A few authors (Appleton, 1964; Christensen, 1971) discussed the possibility of this method but they did not show any results, while we (Nagata et al., 1969) reported the results for the first time. To demonstrate soluble small molecular compounds, we employed cryo-fixation and dry-mounting radioautography for both LMRAG and EMRAG.

\subsection{Techniques of radioautography}

The nuclear emulsions used for radioautography are sensitive for radiation and consist of gelatin matrix and silver bromide crystals. The silver bromide crystals are uniform in size ranging from 70 to 400 $\mathrm{nm}$ in diameter depending on their brands produced by several photo-industry makers in the world such as Konica (Japan), Eastman-Kodak (USA), Ilford (UK). Several kinds of emulsions are commercially available in any countries. They are classified into four types, i. e., gel form or bulk liquid emulsions for light and electron microscopy, stripping films for LMRAG, coated plates or films for macro-RAG and LMRAG, and coated films for macro-RAG. We prefer to use bulk liquid emulsions, Konica NR-M2 for LMRAG and Konica NR-H2 for EMRAG, produced by Konica Co. Tokyo, Japan, because of their fine grains and high sensitivity.

There are various techniques published for applying radioautographic emulsions to the specimens, depending on the kinds of specimens and radioactive compounds to examine. The procedures should be described in detail according to the methodologies employed in the following sections. After the specimens are made contact with the emulsions, they are kept in a cold $\left(4^{\circ} \mathrm{C}\right)$ dark room, usually in a light tight slide box kept in a refrigerator, for exposure for several weeks and finally developed. The development is a chemical reaction to reduce the silver bromide crystals in a developer and to convert 
them to metallic silver grains. When the emulsion is soaked in a developer, the developer reduces the silver bromide crystals which contain specks of latent images building more and more metallic silver around the latent image. The size of silver grains depends on the constituents of the developer as well as the time and temperature of development. The standard developers such as Kodak D-19 or Konica $\mathrm{SD}-\mathrm{X} 1$ consist of some reducing reagents such as methol and hydroquinone, which are abbreviated as MQ developers. When MQ developers are used for both LM and EMRAG, large spiral silver grains as long as a few $\mu \mathrm{m}$ are grown, which can be observed by light microscopy without problems but are too large for electron microscopy. On the contrary, when a fine grain developer such as gold latensification and phenidon developer at a low temperature and shorter time is used, small dot-like silver grains less than $1 \mu \mathrm{m}$ in diameter are produced, which are preferable for electron microscopy (Nagata, 1992, 1996a, 1997a, 1998a, 2002a). We prefer to use this method.

\subsubsection{Light microscopic radioautography}

In order to observe the specimens by light microscopy, localizing the RI-labeled compounds in cells and tissues, the procedure for preparing light microscopic radioautographs can be divided into 2 , the wet-mounting and dry-mounting methods. The former method applies wet emulsions to the specimens and can demonstrate only the insoluble RI-labeled compounds incorporated into macromolecules of cells, while the latter applies dry emulsions and can demonstrate not only the insoluble compounds but also the soluble RI-labeled compounds which are such small molecular compounds and diffusible such as inorganic ions, vitamins and precursors for macromolecular compounds.

For demonstrating only insoluble compounds such macromolecules as nucleic acids (DNA and RNA), proteins, glucides and lipids, conventional light microscopic wet-mounting radioautography can be employed. For this procedure, the same tissue blocks for electron microscopy, which were conventionally fixed in buffered glutaraldehyde and osmium tetroxide solutions then embedded in epoxy resin, are cut on a Porter-Blum MT-2B ultramicrotome at $2 \mu \mathrm{m}$ thickness, picked up onto clean glass slides and warmed for extension and drying. Otherwise, conventional formalin fixed, paraffin embedded tissues can also be used. In order to produce many radioautograms at once and also to compare each other quantitatively, the following procedures, which were developed in our laboratory (Nagata et al., 1967; Nagata, 1982, 1992, 2002a), should be carried out. With regards to the radioautographic emulsions, several types of emulsions are commercially available such as Konica (Japan), Kodak (USA) or Illford (UK). We prefer Konica emulsion (Konica NR-M2, Konica Ltd., Tokyo, Japan) because of the small sized silver bromide crystals and better sensitivity. However, any other emulsions can alternatively used. A bottle of bulk emulsion, is melted in a water bath at $45^{\circ} \mathrm{C}$ for about $10 \mathrm{~min}$, to which an equal amount of distilled water is added and mixed for 5-10 min. with a glass slide to remove all air bubbles. Then, a slide holder, made of stainless steal, holding 15 glass slides which carry several thick sections, is dipped into the melted emulsion for several seconds, then they are pulled up vertically for about $3 \mathrm{~s}$ to assure equal thickness coating $(3-4 \mu \mathrm{m})$ over the sections. The faster the speed is, the thinner becomes the emulsion coating. The bottom of the slide holder is wiped with a paper towel to remove excess emulsion and the slide holder is placed in an electric incubator at $28^{\circ} \mathrm{C}$ with a humidity about $80 \%$, containing a wet sponge at the bottom, and dried for $1 \mathrm{~h}$. When the slides are dry, they are stored in a light tight slide box containing a desiccant (silica gel). After the edge of the box is sealed with black tape, it is kept in a refrigerator at $4^{\circ} \mathrm{C}$ for exposure. After an appropriate exposure time, all the slides are developed at once by pouring the developer into the slide box. We use Konica KD-X1 (formerly SD-X1) developer for Konica NR-M2 emulsion. Kodak D-19 may be used for any type of emulsions. After the development, the slides are rinsed in stop bath ( $2 \%$ aqueous acetic acid solution), fixed in a fixer ( $30 \%$ aqueous sodium thiosulphate solution) for 5 min twice, washed gently in running tap water for $10 \mathrm{~min}$, and finally they are stained in $1 \%$ toluidine blue solution for light microscopy.

In order to demonstrate soluble compounds, conventional procedures such as chemical fixation in water, dehydration, embedding of tissues, sectioning using water, and wet-mounting radioautography with wet emulsion cannot be applied. Only cryo-sectioned and freeze-dried specimens or freeze-dried or freeze-substituted and embedded specimens without water should be dry-sectioned and coated with dry radioautographic emulsions without using any water. This procedure is designated as dry-mounting radioautography. The procedures for dry-mounting radioautography can be divided into two, light microscopic and electron microscopic procedures. Historically various procedures were employed in the literature for light microscopic dry-mounting radioautography as described previously (Nagata, 1994a, 1998a; Nagata \& Murata, 1977). Since the first application of cryostat sections on precoated slides at very 
low temperature, many authors recommended this technique at the light microscopic level. However, those procedures are very much complicated to treat both specimens and emulsions. We first used dry-films produced with a large wire-loop which were air-dried and applied to cryostat sections placed on glass slides (Nagata \& Nawa, 1966). We believe that this method is the most convenient one. Radioautographic emulsion is diluted equal part with distilled water at $45^{\circ} \mathrm{C}$. We use Konica NR-M2 emulsion (Konica Ltd., Tokyo, Japan). Any other emulsions such as Kodak can alternatively be used. Ten ml of diluted emulsion are added with $0.2 \mathrm{ml}$ at $2 \%$ aqueous solution of dioctyl sodium sulfosuccinate (a surfactant) in order to prevent the emulsion film from bursting (Nagata \& Nawa, 1966). A thin film of emulsion is obtained by dipping a wire-loop, $2.5 \mathrm{~cm}$ in diameter, which is made of platinum wire or vinyl coated iron wire and set with a piece of Scotch tape on a glass slide as a handle. The handle is set horizontally on a flat desk for air-drying. After air-drying for 1-2 min., when the center of emulsion film is gelled and dried appearing transparent but the peripheral zone is still wet appearing opaque, the film is applied to the slide horizontally. The glass slide is kept in a Petri dish and warmed at $28^{\circ} \mathrm{C}$ in an incubator for $1 \mathrm{~h}$ for drying the emulsion. After an appropriate exposure time, the glass slides are processed for development, then stopped in stop bath, fixed in a fixer and stained with toluidine blue solution for staining. Control tissues should be fixed with chemical fixative, dehydrated, embedded, wet-sectioned and wet-mounted by conventional dipping procedure.

\subsubsection{Electron microscopic radioautography}

In order to observe the specimens by electron microscopy, localizing the RI-labeled compounds at cells organelle level, we employ the procedure for preparing electron microscopic radioautographs which can be divided into 2, the wet-mounting and dry-mounting methods. The former method applies wet emulsions to the specimens and can demonstrate only the insoluble RI-labeled compounds incorporated into macromolecules of cells, while the latter applies dry emulsions and can demonstrate not only the insoluble compounds but also the soluble RI-labeled compounds which are such small molecular compounds and diffusible such as inorganic ions, vitamins and precursors for macromolecular compounds.

For demonstrating only insoluble compounds such macromolecules as nucleic acids (DNA and RNA), proteins, glucides and lipids, conventional electron microscopic wet-mounting radioautography can be employed. For this procedure,we use the same embedded tissues in epoxy resin for both LMRAG and EMRAG. For EMRAG, ultrathin sections at $0.1 \mu \mathrm{m}(100 \mathrm{~nm})$ or semithin sections at $0.2 \mu \mathrm{m}(200$ $\mathrm{nm}$ ) are cut on an ultramicrotome and picked up on collodion coated copper grid meshes. The semithin sections should be observed by high voltage electron microscopy (Nagata, 1995b).

With regards to the radioautographic emulsions for electron microscopy, several types of emulsions are commercially available. We use Konica NR-H2 emulsion (Konica Ltd., Tokyo, Japan) because of the small sized silver bromide crystals and better sensitivity. To obtain thin monolayer of silver bromide crystals, two techniques, dipping and wire-loop methods, are now in general use. The choice lies between mounting the sections on a flat microscopic glass slide or on a grid mesh during the exposure. By the former method, glass slides are covered with thin collodion films on which sections are placed and they are coated with radioautographic emulsion by dipping similarly to the light microscopic procedure. After exposure and photographic processing, the sections and collodion films together with the emulsion are floated off the glass slide and picked up on a grid for examining by electron microscopy. This procedure is called a flat substrate method and practically very much complicated and troublesome. We do not prefer this method. On the other hand, by the latter method, sections are placed on grid meshes coated with collodion films according to the normal sectioning method and are covered with a preformed monolayer emulsion by picking up thin bubbles of molten emulsion on a wire-loop and allowing it to gel before touching it on the grids. This is called wire-loop method. We prefer this procedure, which was developed at our laboratory, using either small wire-loops or larger wire-loops (Nagata, 1992, 1996a, 1997a, 1998a, 2002a). Our procedure will be described in detail as follows (Nagata, 2002a).

A regular square glass block, whose length of each side is $1.25 \mathrm{~cm}$, is made from the glass strips No. 4890-40 for LKB knife maker (LKB-Produkter AB, Bromma, Sweden). A square piece of double-coated Scotch tape, $4 \mathrm{~mm}$ in length, is stuck on the surface of each glass block. Six grids are placed around the tape like a rosette, arranged clockwise to identify each grid. The grids are vacuum coated with carbon at $10 \mathrm{~nm}$ thickness. Radioautographic emulsion is diluted equal part with distilled water at $45^{\circ} \mathrm{C}$. We use Konica NR-H2 emulsion (Konica Ltd., Tokyo, Japan). Any other emulsions such as Kodak can alternatively be used. Ten $\mathrm{ml}$ of diluted emulsion is added with $0.2 \mathrm{ml}$ at $2 \%$ aqueous solution of dioctyl sodium sulfosuccinate (a surfactant) in order to prevent the emulsion film from bursting (Nagata et al., 
1967). A thin film of emulsion is obtained by dipping a wire-loop, $2.5 \mathrm{~cm}$ in diameter, which is made of platinum wire or vinyl coated iron wire. After air-drying horizontally for $1 \mathrm{~min}$., when the emulsion film is gelled but still wet, the film is applied to the grids on the glass block horizontally. The glass block is warmed at $28^{\circ} \mathrm{C}$ for $1 \mathrm{~h}$ for drying the emulsion. For exposure, several glass blocks are attached to one side of a microscopic slide with double-coated Scotch tape. Control emulsion films should be checked by electron microscopy before the exposure. Several glass slides, carrying several glass blocks, respectively, are placed in a black light tight plastic slide box which contains desiccant (silica gel), and the top is sealed with black tape. The slide box is kept in a refrigerator at $4^{\circ} \mathrm{C}$ for exposure. After an appropriate exposure time, the glass slides carrying glass blocks with grid meshes are processed for development, then stopped in stop bath, fixed in a fixer and stained with lead citrate solution for electron staining. Concerning the development of the emulsions, when a conventional MQ-developer such as D-19 is used, long spiral silver grains are formed. In order to obtain smaller silver grains, phenidon developer after gold latensification $(\mathrm{G}-\mathrm{L})$ is recommended.

In order to demonstrate soluble compounds, conventional procedures such as chemical fixation in water, dehydration, embedding of tissues, sectioning using water, and wet-mounting radioautography with wet emulsion cannot be applied. Only cryo-sectioned and freeze-dried specimens or freeze-dried or freeze-substituted and embedded specimens without water should be dry-sectioned and coated with dry radioautographic emulsions without using any water. This procedure is designated as dry-mounting radioautography. For electron microscopic dry-mounting radioautography, the grids carrying dry sections (either freeze-dried or freeze-substituted Epon embedded sections or freeze-sectioned and freeze-dried) are coated with carbon at 5-10 $\mathrm{nm}$ thick before emulsion application. They are then put on a grid holder made of a glass slide $(25 \mathrm{~mm} \times 75 \mathrm{~mm})$ and 3 glass rods $(3 \mathrm{~mm}$ in diameter and $10 \mathrm{~mm}$ in length, respectively (Nagata et al., 1969). Radioautographic emulsion is diluted 1 part in 10 with distilled water at $45^{\circ} \mathrm{C}$ in the dark room. Ten $\mathrm{ml}$ of the diluted emulsion is added to $0.2 \mathrm{ml}$ of $2 \%$ aqueous solution of dioctyl sodium sulfosuccinate and is maintained at $45^{\circ} \mathrm{C}$ in a thermobath for several minutes to complete mixing. Dioctyl sodium sulfosuccinate, a surface activating agent is used to prevent the emulsion films from bursting while they are being dried in the air (Nagata et al., 1969). We use Konica NR-H2 emulsion, produced by Konica Co., Ltd., Tokyo, Japan. Other emulsions for electron microscopic radioautography such as Kodak NTB or Ilford L4 can be used in a similar way. A thin film of the emulsion thus prepared is obtained by dipping a platinum wire loop, about $1 \mathrm{~cm}$ in diameter, into the emulsion. Instead of a small platinum wire loop, a large vinyl coated iron wire loop, $2.5 \mathrm{~cm}$ in diameter, can also be used (Nagata, 1992, 2002a). The handle of the wire loop is set on a flat surface for air-drying (for 1-2 min). The films are almost $100 \%$ air-dried without breaking by use of dioctyl sodium sulfosuccinate solution. The dried films are then applied to the grids on the holders like quoits. The grids are then transferred into Petri dishes and are warmed at $37^{\circ} \mathrm{C}$ for $1 \mathrm{~h}$ to help the films adhere to the grids. They are exposed, developed, fixed and stained simultaneously.

\section{Application of Radioautography to the Eye}

The visual organ consists of the eye and its accessory organs. The eyeball of vertebrates consists of the ocular wall and the contents. The ocular wall can be divided into 3 layers, from external to internal, the external tunic (Tunica externa) or fibrous tunic (Tunica fibrosa), the median tunic (Tunica media) or vascular tunic (Tunica vasculosa) or uvea and the internal tunic (Tunica externa). The external layer consists of the cornea and the sclera. The median tunic consists of the iris, ciliary body and choroid. The internal layer consists of the pigment epithelium and the retina. The contents of the eyeball are refractile media of the eyeball are the aqueous humor in the anterior and posterior chambers, the lens and the vitreous body. The accessory organs are the eyelids, the conjunctiva and the lacrimal apparatus. We have studied the macromolecular synthesis, DNA, RNA, proteins and glucides in the ocular tissues of chick embryos in incubation as well as prenatal and postnatal mice at various ages in aging (Nagata, 1998c, 2000). Thus, this review deals with the application of radioautography to both avian and mammalian ocular tissues in aging.

\subsection{The external layer of the eyeball (Tunica fibrosa)}

The external layer or external tunic of the eyeball is designated as tunica fibrosa or fibrous tunic. It consists of the sclera and the cornea. The anterior one-sixth is the cornea and the posterior five-sixth is the sclera. We first studied the ocular tissues of chick embryos. The ocular tissues of white 
Leghorn chick embryos labeled with either ${ }^{3} \mathrm{H}$-thymidine demonstrating DNA synthesis or ${ }^{3} \mathrm{H}$-uridine demonstrating RNA synthesis were studied (Gunarso, 1984a,b; Gunarso et al., 1997). Then, we studied the ocular tissues of mice, rats and rabbits.

\subsubsection{The sclera}

The incorporation of ${ }^{3} \mathrm{H}$-thymidine into DNA was examined in the sclera and the retina of chick embryos in early developmental stages during the period of the optic vesicle formation (day 2) to the basic layer formation (day 7) by means of LM and EM RAG (Fig. 1). Fresh fertilized white Leghorn chicken eggs were purchased from a local hatchery (Komatsu Hatchery, Matsumoto, Japan) and the eggs were incubated in a moist incubator at $38.5^{\circ} \mathrm{C}$ for $2,3,4$ and 7 days embryonic ages (stages 9-12, 14-20, 23-24, and 31-32 of Hamburger and Hamilton, 1951). The eyeballs were taken out and dissected in Hanks' balanced salt solution. The tissue pieces were cultured in vitro in Eagle's MEM supplemented with $10 \%$ calf serum containing ${ }^{3} \mathrm{H}$-thymidine at a concentration of $1.8 \mathrm{MBq} / \mathrm{ml}$ in a $\mathrm{CO}_{2}$ incubator for $1 \mathrm{~h}$, fixed in buffered $2.5 \%$ glutaraldehyde and $1.0 \%$ osmium teroxide, dehydrated, embedded in epoxy resin, sectioned and radioautographed. The results showed that some mesenchymal cells surrounded and proliferated around the optic vesicles of chick embryos forming the scleral tissues from day 2 to 3, 4 and 7 (Fig. 2A,B,C). The numbers of labeled fibroblasts with ${ }^{3} \mathrm{H}$-thymidine demonstrating DNA synthesis were the highest on day 2 and decreased to day 3, 4 and 7, similarly to the retinal cells (Gunarso et al., 1997).

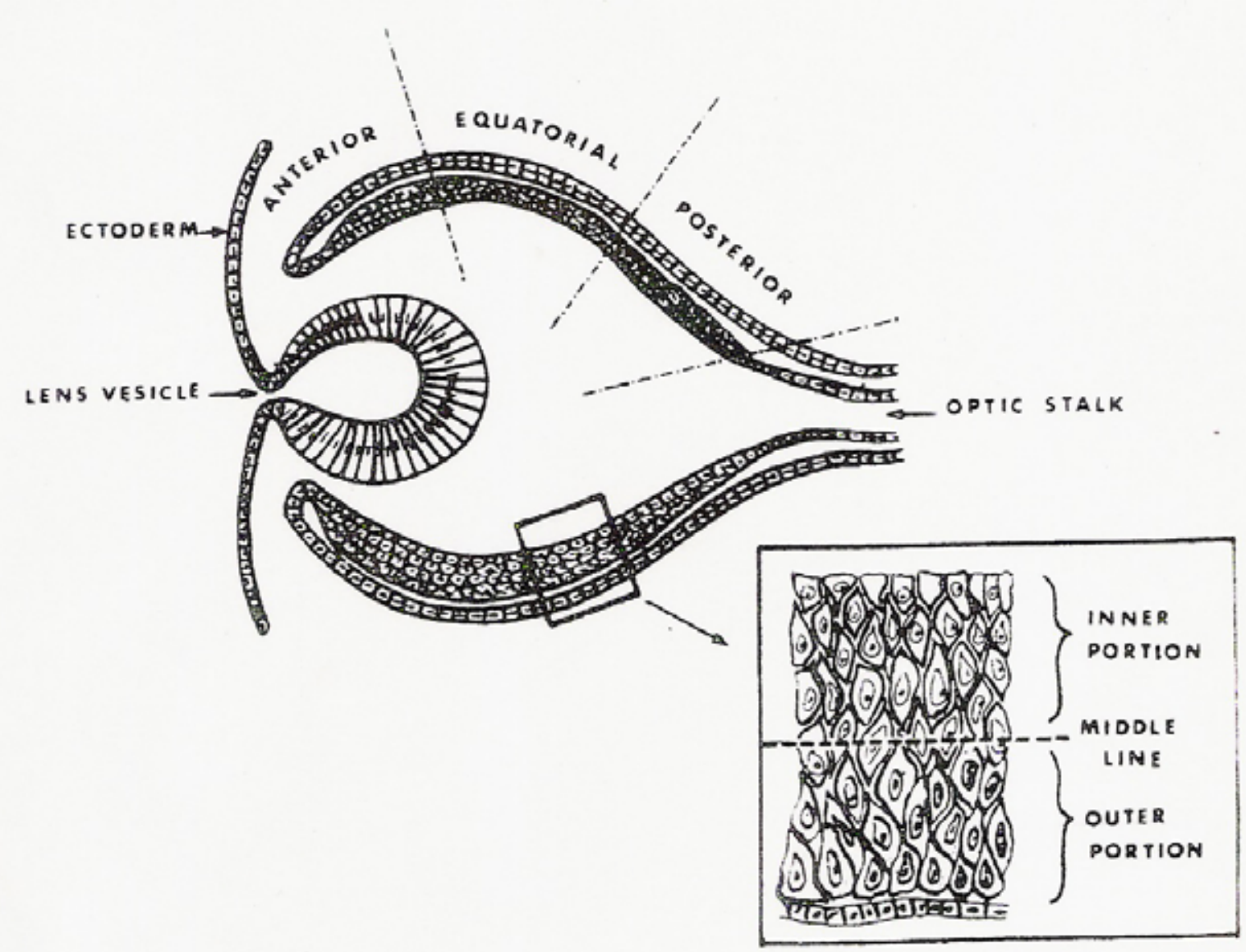

Figure 1. Diagram of the structure of chick embryo optic vesicle showing 3 regions where the labeled cells were observed. Insert shows magnification of the inner and outer layers. From Gunarso et al. (1997). 


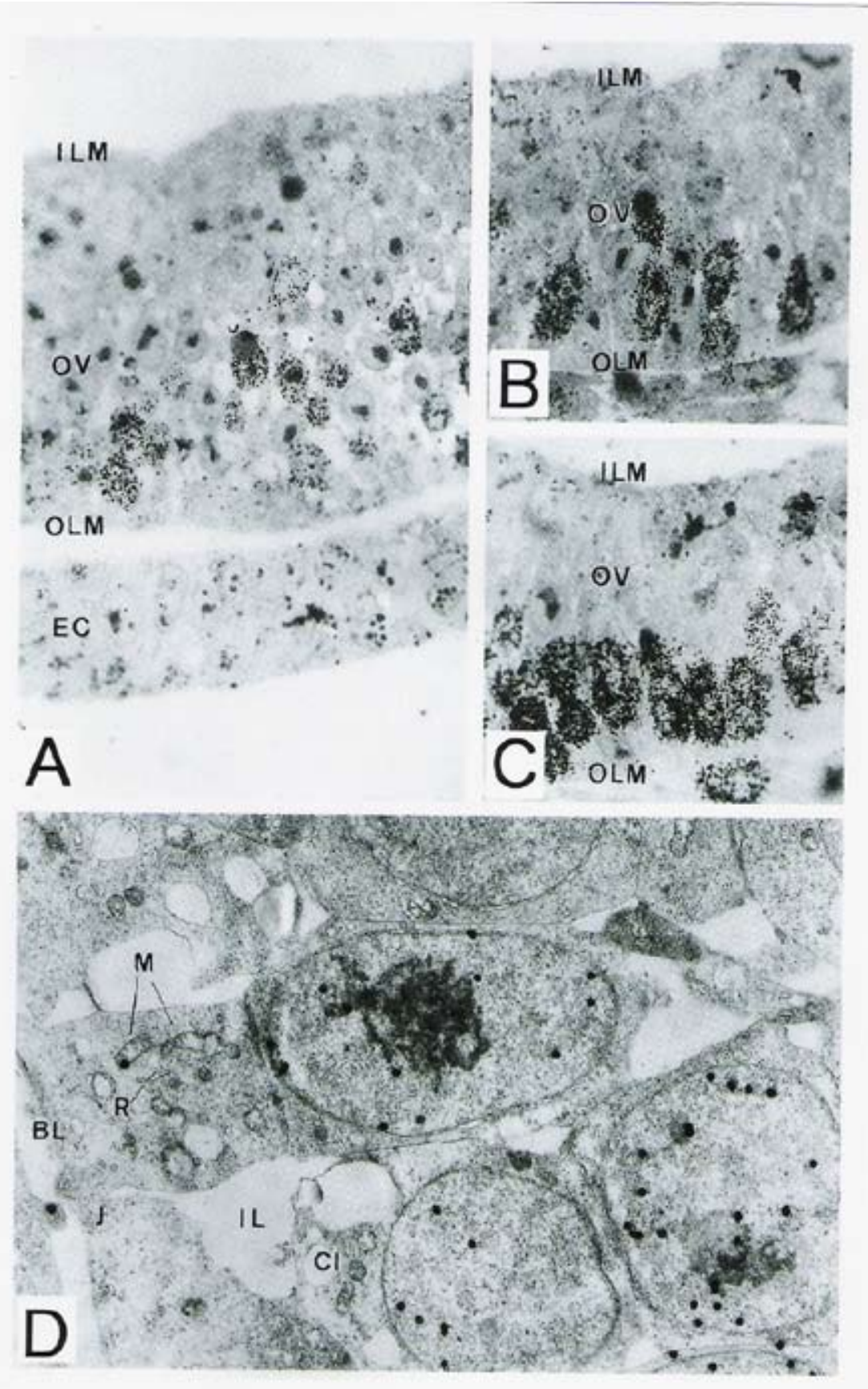

Figure 2. Light microscopic (LM) and electron microscopic (EM) radioautograms (RAG) of the optic vesicles of chick embryo retinas at day 2, labeled with silver grains due to ${ }^{3} \mathrm{H}$-thymidine showing DNA synthesis after $1 \mathrm{hr}$ incubation in vitro. 2A,B,C. LMRAG of the anterior region (2A), equatorial region (2B) and posterior region (2C) of a day 2 chick embryo, showing the localization of the labeled cells in the outer portion of the optic vesicle layer. $\mathrm{x} 780$. 2D EMRAG of the anterior region of a day 2 chick embryo, showing the localization of the labeled cells in the outer portion of the optic vesicle layer. Note that one of the mitochondria $(\mathrm{M})$ at the left corner of the figure is labeled with a silver grain. IML: inner limiting membrane, OLM: outer limiting membrane, OV: optic vesicle, BL: basal lamina, IL: intercellular lacunas, J: intercellular junction. x10,000. From Gunarso et al. (1997).

When the tissue pieces of chicken embryos were cultured in vitro in Eagle's MEM supplemented with $10 \%$ calf serum containing ${ }^{3} \mathrm{H}$-uridine at a concentration of $1.8 \mathrm{MBq} / \mathrm{ml}$ in a $\mathrm{CO}_{2}$ incubator for 1 $\mathrm{h}$, fixed in buffered $2.5 \%$ glutaraldehyde and $1.0 \%$ osmium teroxide, dehydrated, embedded in epoxy resin, sectioned and radioautographed, RNA synthesis was observed in almost all the fibroblasts in the mesenchymal cells surrounding the optic vesicles forming the scleral tissues (Fig. 3A,B,C). The numbers of silver grains in the cells increased from day 2 to 3,4 and 7, similarly to the retinal cells, showing the increase of RNA synthesis (Gunarso et al., 1996). 


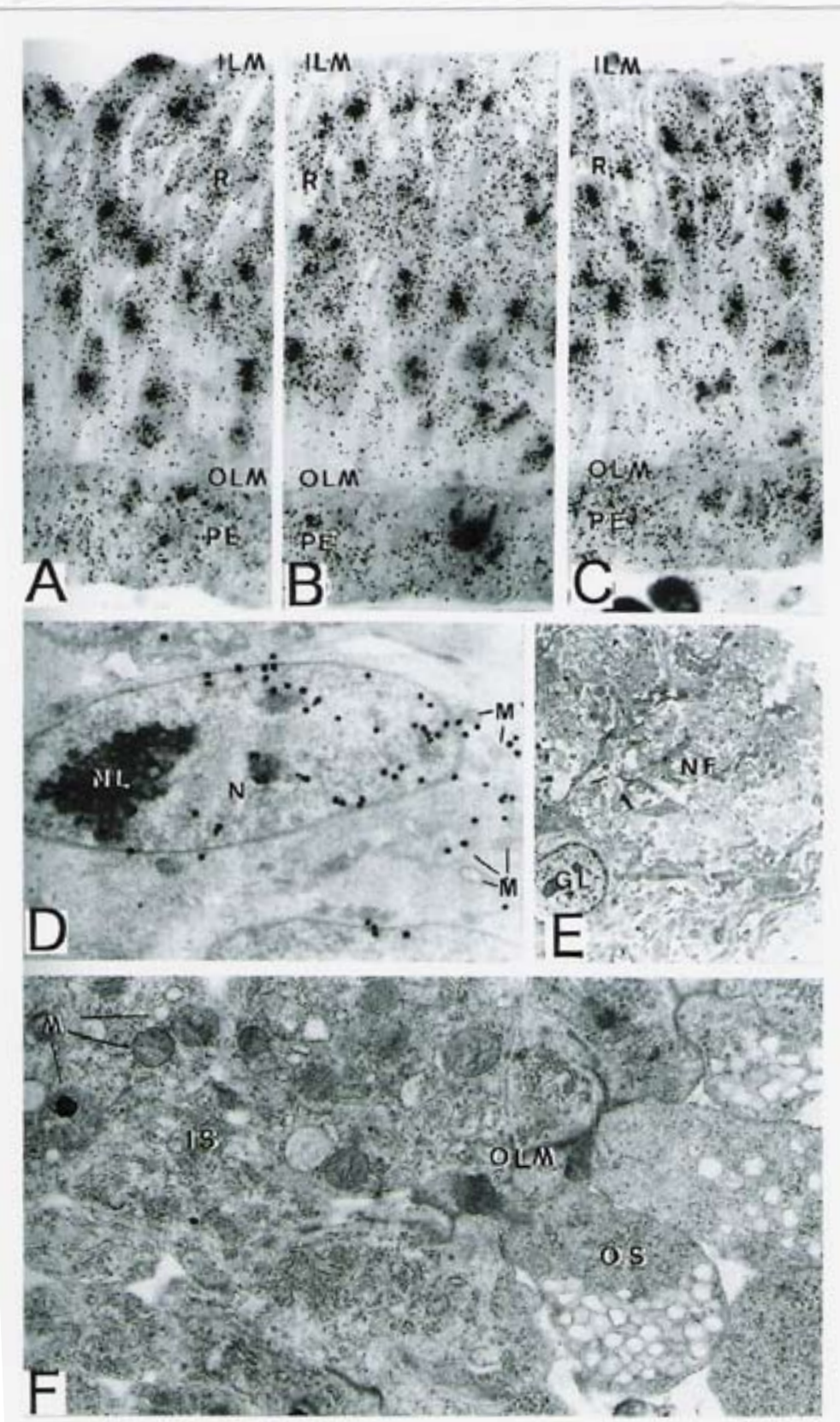

Figure 3. LMRAG (3A,B,C) and EMRAG (3D,E,F) of day 7 embryo retinas $1 \mathrm{hr}$. after incubation in vitro with ${ }^{3} \mathrm{H}$-uridine showing DNA synthesis. 3A. Anterior region. x540. 3B. Equatorial region. x 540. 3C. Posterior region. $x 540.3 \mathrm{D}$. Anterior region showing a labeled cell labeled with silver grains over the euchromatin, nuclear membrane, nucleolus and ribosomes. x4400. 3E. A ganglion cell with a developed axon. x1600. 3F. A developing photoreceptor cell with outer segment (OS). x9500. From Kong et al. (1992b).

On the other hand, the ocular tissues obtained from groups of litter ddY mice at various ages varying from fetal day $9,12,14,16,19$ to postnatal day $1,3,8,14$, month $1,2,6$ and year 1 were labeled with ${ }^{3} \mathrm{H}$-thymidine by intraperitoneal injections and radioautographed (Kong et al., 1992a,b; Gao et al., 1992a,b). The results showed that mesenchymal cells surrounded and proliferated around the optic vesicles of embryos forming the scleral tissues from embryonal day 9 to 18 , forming sclera on postnatal day 1, 3, 7, 14 (Fig. 4A,E). The numbers of labeled fibroblasts with ${ }^{3} \mathrm{H}$-thymidine demonstrating DNA synthesis decreased from embryonal day 9 to postnatal day 14 (Kong et al., 1992a,b) and further to month 6 , reaching zero at month 12 or year 1 (Gao et al., 1992a,b). 


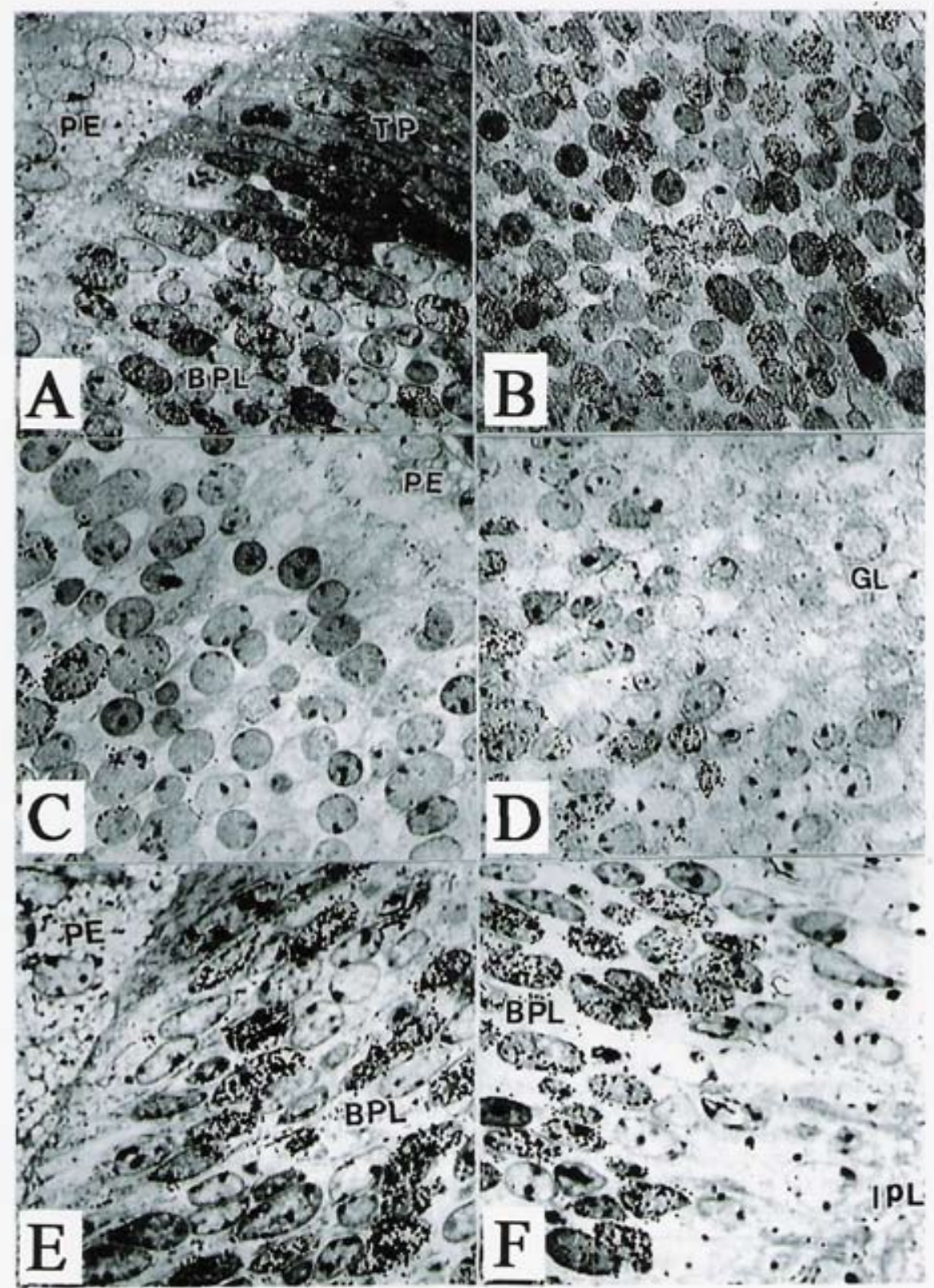

Figure 4. LMRAG of mouse retinas at embryonic day 19 and postnatal day $1,1 \mathrm{hr}$ after injection with ${ }^{3} \mathrm{H}$-thymidine showing the localizations of labeled cells in the undifferentiated bipolar photoreceptor layer (PBL) at embryonic day 19. 4A. The anterior region and the transitional portion (TP) of the retina and pigment epithelium (PE). x1140. 4B. The equatorial region showing the bipolar-photoreceptor layer at embryonic day 19. x1150. 4C.The posterior region showing a part of the bipolar-photoreceptor layer beneath the pigment epithelium at embryonic day 19. x1220. 4D. The posterior region showing a part of the bipolar-photoreceptor layer near the ganglion layer at embryonic day 19. $\mathrm{x} 1120$. 4E.The anterior region showing the labeled cells in the bipolar-photoreceptor layer at postnatal day 1 . $\mathrm{x} 1500.4 \mathrm{~F}$. The equatorial region showing the labeled cells in the bipolar-photoreceptor layer at postnatal day 1 . x1600. From Gao et al. (1992b).

The ocular tissues obtained from other groups of litter ddY mice at various ages varying from fetal day $9,12,14,16,18$ to postnatal day $1,3,7,14$ were labeled with ${ }^{3} \mathrm{H}$-uridine in vitro and radioautographed (Kong et al., 1992a,b). RNA synthesis was observed in the fibroblasts in the mesenchymal cells surrounding the optic vesicles forming the scleral tissues of embryonic day 9 to postnatal day 14 (Fig. 5A,B,C,D). The numbers of silver grains in the cells increased from embryonic day 9 to 18, then to postnatal day 7 and decreased to day 14, showing an increase and decrease of RNA synthesis in the sclera (Kong et al., 1992a,b). 


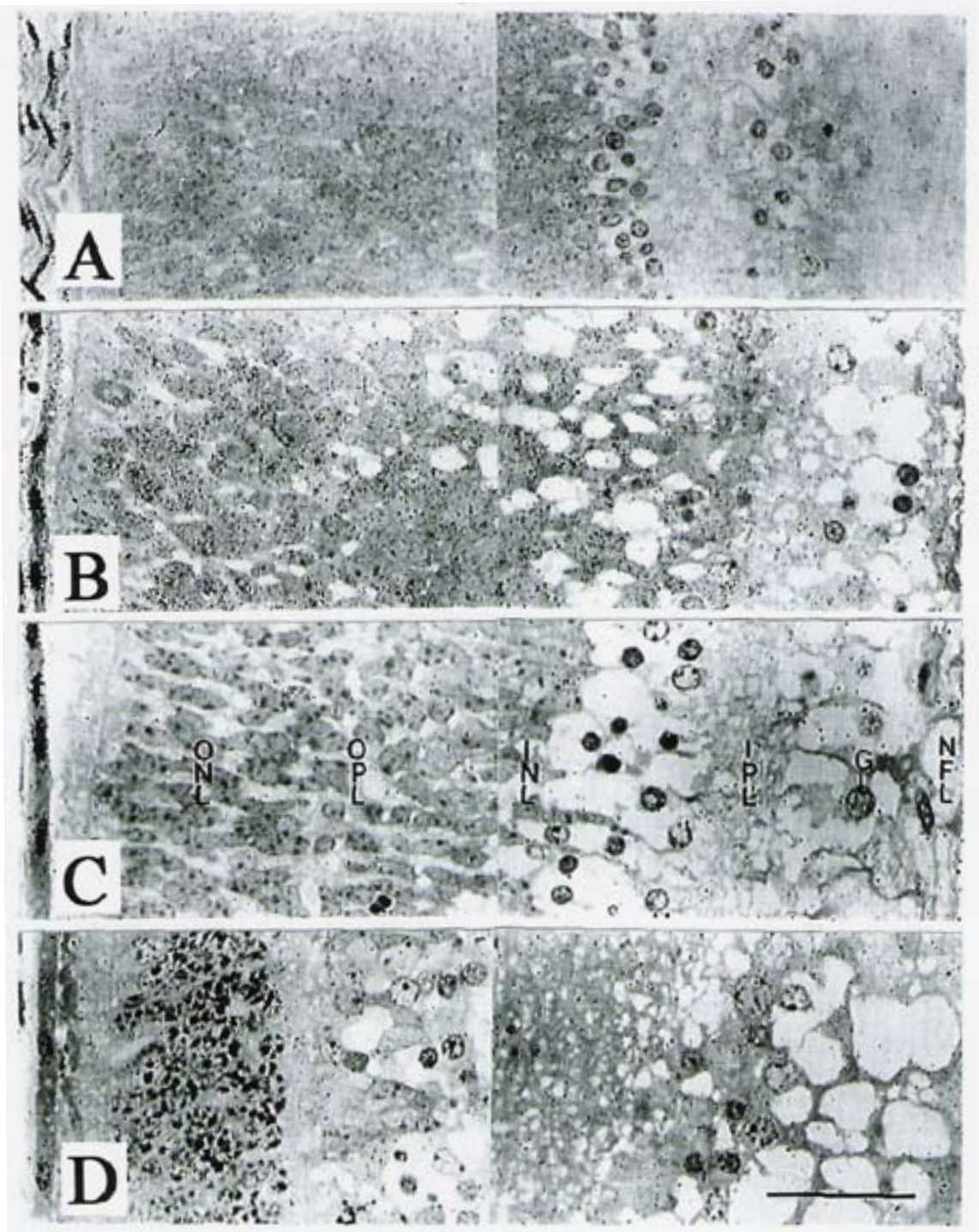

Figure 5. LMRAG of mouse retinas at postnatal day 1, 3, 7 and 14, $1 \mathrm{hr}$ after injection with ${ }^{3} \mathrm{H}$-uridine showing the localizations of labeled cells in the scleral portions corresponding to the photoreceptor cells. $\mathrm{x} 750.5 \mathrm{~A}$. Postnatal day 1. 5B. Postnatal day 3. 5C. Postnatal day 7. 5D. Postnatal day 14. ONL: outer nuclear layer. OPL: outer plexiform layer. INL: inner nuclear layer. IPL: inner plexiform layer. GL: gaglion cell layer. NFL: nerve fiber layer. From Kong et al. (1992b).

In the sclera of aging mice, the distribution and localization of TGF $\beta 1$ and $\beta F G F$, and their mRNAs, were studied by means of immunostaining and in situ hybridization using ${ }^{35} \mathrm{~S}$-labeled oligonucleotide probes (Nagata \& Kong 1998). The posterior segments of BALB/c mouse eyes, from embryonic day $14,16,19$, and postnatal day $1,3,5,7,14,28,42$ and 70 were used as materials. The results showed that positive immunoreactivities of TGF $\beta 1$ localized in the sclera which showed weak reactions in the sclera at embryonic day 14 (Fig. 6A), moderately positive at embryonic day 16 (Fig. 6B), and intense reactions from postnatal day 1 (Fig. 6C), week 4 (Fig. 6D) to week 10. For in situ hybridization, ${ }^{35}$ S-labeled oligonucleotide probes for TGF- $\beta 1$ and $\beta F G F$ were used to detect their mRNAs. Cryosections were picked up on glass slides which were processed for in situ hybridization and radioautographed. As the results, the silver grains which represented the hybridization with ${ }^{35} \mathrm{~S}$-labeled antisense oligonucleotide probe for TGF $\beta 1$ and $\beta$ FGF mRNAs mainly located in the scleral layers. In the radioautograms from embryonic day 14 to adult mice (10 weeks), significant silver grains were detected in scleral and mesenchymal cells at E14 (Fig. 6E) and E16, then the number of grains increased in these layers particularly in sclera from E19 (Fig. 6F) to postnatal neonate (Fig. 6G) to 1 week (Fig. 6H) until adult, showing that mRNAs for these growth factors were synthesized in the sclera from embryo to adult stages. These results suggested that mRNAs for TGF- $\beta 1$ and $\beta$ FGF were synthesized in scleral layers, but their proteins were transferred to the target cells of the retina and elsewhere (Nagata \& Kong, 1998). 


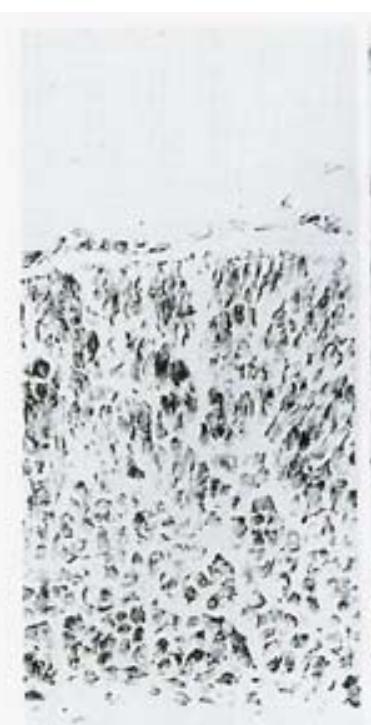

\section{A}

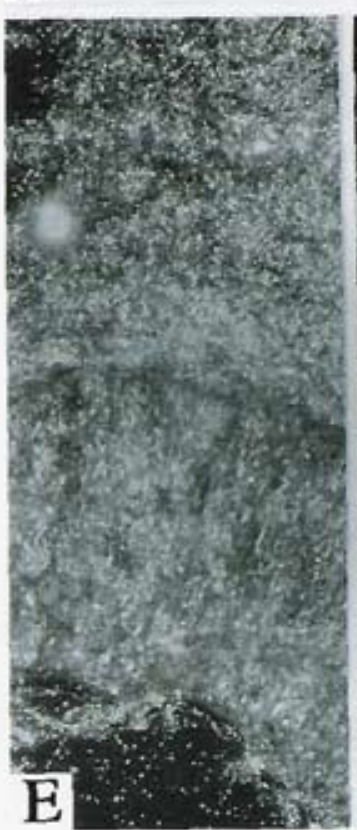

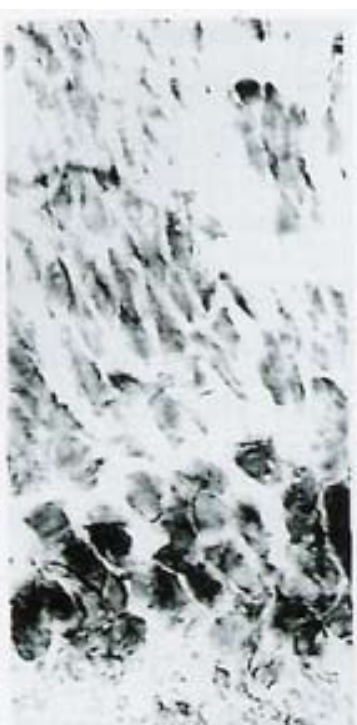

B

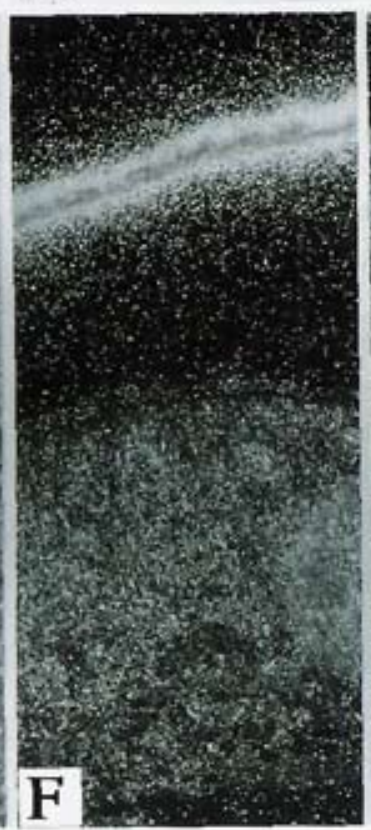

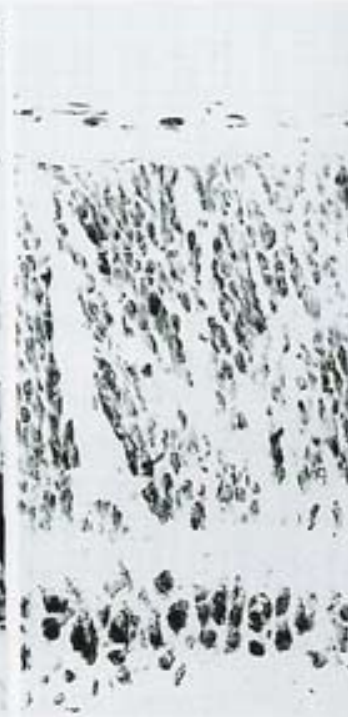
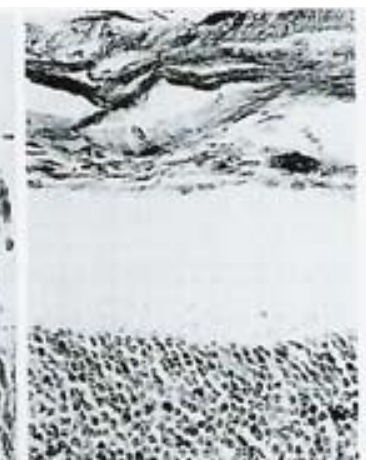
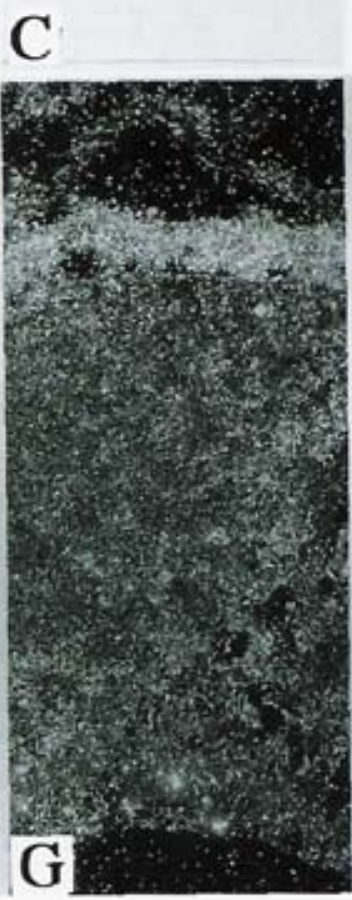

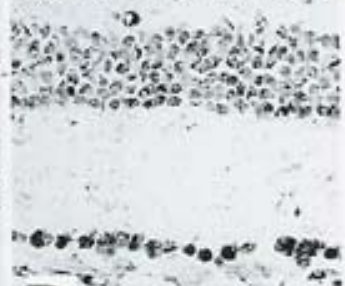

D

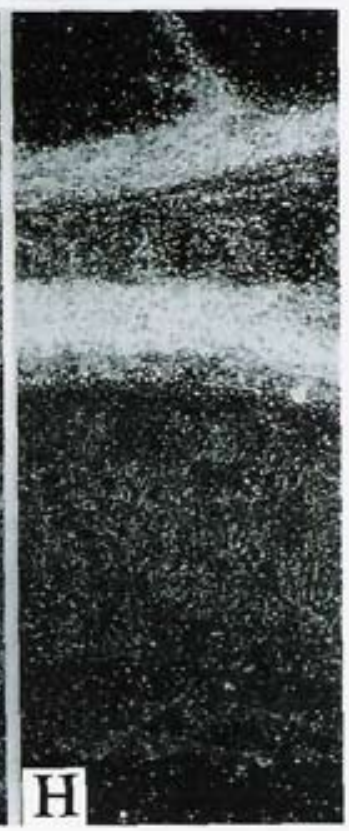

Figura 6. Immunostaining and LMRAG of mouse ocular tissues at embryonic day 14, 16 and postnatal day 1, week 1 and 4 , showing distribution and localization of the transforming growth factors, TGF $\beta 1$ and bFGF by immunostaining (6A,B,C,D) and their mRNAs by in situ hybridization (6E,F,G,H). 6A. Weak immunostaining at embryonic day 14 . 6B. Moderate immunostaining at embryonic day 16. 6C. Intense immunostaining at postnatal day 1. 6D. Intense immunostaining at postnatal week 4. 6E. In situ hybridization for TGF $\beta 1 \mathrm{mRNA}$, showing a few silver grains over the scleral layer at embryonic day 14. 6F. In situ hybridization for TGF $\beta 1 \mathrm{mRNA}$, showing intense silver grains over the scleral layer at embryonic day 19. 6G. In situ hybridization for TGF $\beta 1 \mathrm{mRNA}$, showing intense silver grains over the scleral layer at postnatal day $1.6 \mathrm{H}$. In situ hybridization for TGF $\beta 1 \mathrm{mRNA}$, showing intense silver grains over the scleral layer at postnatal day 14 (week 1). From Nagata and Kong (1998).

\subsubsection{The cornea}

The corneal tissues, from both central and peripheral zones of aging mice at various ages, from embryonic day 18 to postnatal day 1, 3, 7, 14, month 1, 6 and 12 (year 1), were studied by light and electron microscopic radioautography after intraperitoneal injections of ${ }^{3} \mathrm{H}$-thymidine, ${ }^{3} \mathrm{H}$-uridine, ${ }^{3} \mathrm{H}$-leucine and ${ }^{3} \mathrm{H}$-glucosamine. When the corneal tissues of aging mice were labeled with ${ }^{3} \mathrm{H}$-thymidine at various ages, from embryonic day 19 to postnatal year 1, the labeled cells with silver grains showing DNA synthesis were localized in all the 3 layers of the cornea, the epithelial, stromal and endothelial layers, from embryonic day 19 to postnatal 1 year (Nagata et al., 1990; Nagata, 1993, 1998; Gao et al., 1993). In the epithelial layer, the labeled cells were mainly localized in the basal layer from embryonic 
to postnatal 1 year throughout the studied period (Fig. 7A,B,C). The labeled stromal cells were scattered in the stromal layer from embryonic day 19 to postnatal day 8 (Fig. 7A), but they vanished from month 1 to year 1 . The labeled endothelial cells were few at embryonic day 19, but increased from postnatal day 1 to 3 , then decreased from day 8 to month 1 and year 1 (Fig. 7A). The labeling indices of the corneal epithelial cells in respective aging groups increased from embryonic day 19 to postnatal day 1,8 , reaching a peak (12-13\%) at month 2, and decreased to year 1 (Fig. 8A,B), while the indices of stromal cells (Fig. 8C,D) and endothelial cells (Fig. 8E,F) were low, increased from embryonic day 19 to postnatal day 1,3 , reaching peaks (6-7\%) at 3 days after birth and decreased from day 8 to month 1 and kept 0 from postnatal month 1 to year 1 (Gao et al., 1993).
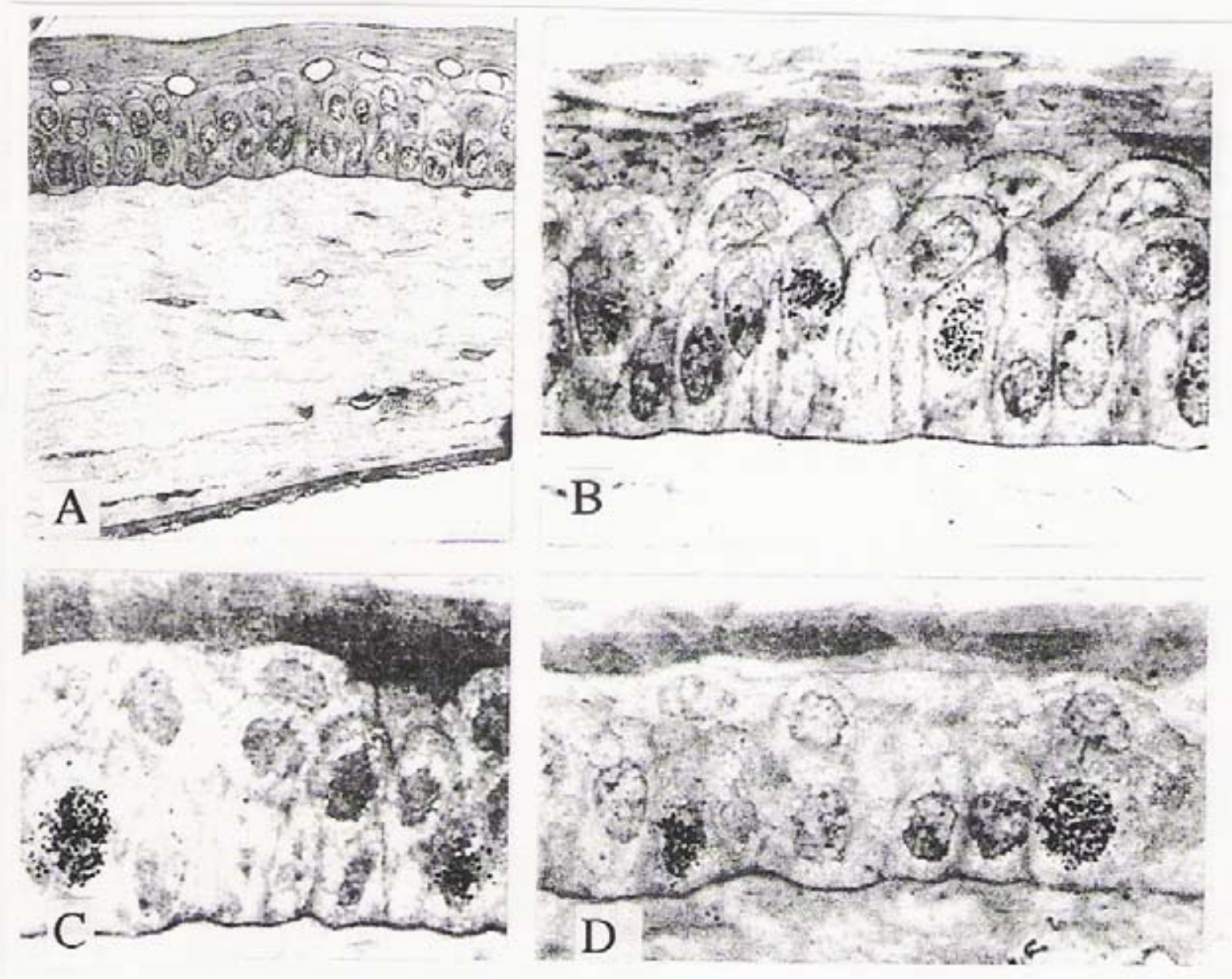

Figura 7. LMRAG of mouse corneas labeled with H-thymidine at month 2 to 12. 7A. Mouse cornea at month 2. Labeled cells are localized in the basal layer of the epithelial layer. $\mathrm{x} 400.7 \mathrm{~B}$. Mouse cornea at month 2, showing the epithelial layer. Labeled cells are localized over the epithelial layer. x1300. 7C. Mouse cornea at month 6. A few labeled cells are found in the basal layer of the epithelial layer. x1550. 7D. Mouse cornea at month 12 (year 1). Only 2 labeled cells are found in the basal layer of the epithelial layer. x1500. From Gao et al. (1993).

When the corneal tissues were labeled with ${ }^{3} \mathrm{H}$-uridine, RNA synthesis was studied in several groups of aging dd $\mathrm{Y}$ mice. Silver grains of both ${ }^{3} \mathrm{H}$-uridine incorporations were located in all the 3 layers of the cornea, the epithelial, stromal and endothelial layers, from embryonic day 19 to postnatal 1 year (Nagata et al., 1990, 1991). In the epithelial layer, almost all the cells were labeled from embryonic to postnatal 1 year throughout the studied period. Most stromal cells and the endothelial cells were also labeled from embryonic day 19 to year 1 . The number of silver grains in the corneal epithelial cells in respective aging groups increased from embryonic day 19 to postnatal day 1, 8, reaching a peak at month 2 , and decreased to year 1, while the number of silver grains in stromal and endothelial cells were low, increased from embryonic day 19 to postnatal day 1, 3, reaching peaks at 3 days after birth and decreased 

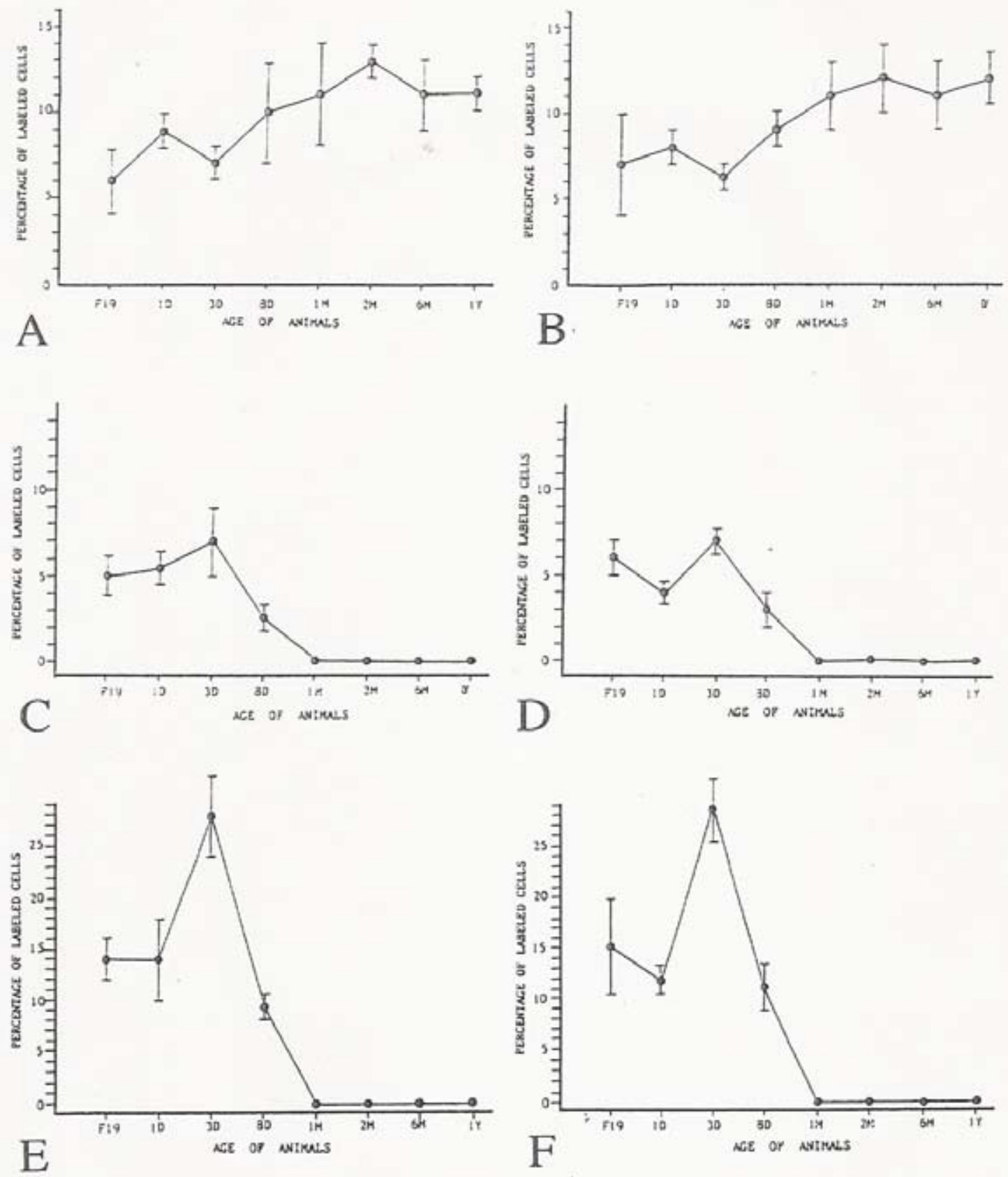

Figura 8. Transitional curves showing average labeling indices of epithelial cells in the peripheral area (8A) and central area (8B), stromal cells in the the peripheral area (8C) and central area (8D), and endothelial cells the peripheral area $(8 \mathrm{E})$ and central area $(8 \mathrm{~F})$ of aging mouse corneas labeled with ${ }^{3} \mathrm{H}$-thymidine at various ages. Mean \pm Standard Deviation. From Gao et al. (1993). Gao et al. (1993).

from day 8 to month 1 and decreased from postnatal month 1 to year 1 .

On the other hand, when the corneal tissues were labeled with ${ }^{3} \mathrm{H}$-leucine, incorporations were studied in several groups of aging ddY mice (Nagata, 1999b, 2000; Cui et al., 2000). Silver grains of ${ }^{3} \mathrm{H}$-leucine incorporations were located in the epithelial cells, the stromal fibroblasts and the endothelial cells from prenatal day 19 to postnatal 6 months (Fig. 9A,B,C,D,E,F). No silver grains were observed in the lamina limitans anterior (Bowman's membrane) and the lamina limitans posterior (Descemet's membrane). The grain densities by ${ }^{3} \mathrm{H}$-leucine incorporation in 3 layers, i. e., epithelial (Fig. 10A), stromal (Fig. 10B) and endothelial (Fig. 10C) layers, increased from embryonic stage to postnatal day 3 and 7 , then decreased to 2 weeks and 1 year 

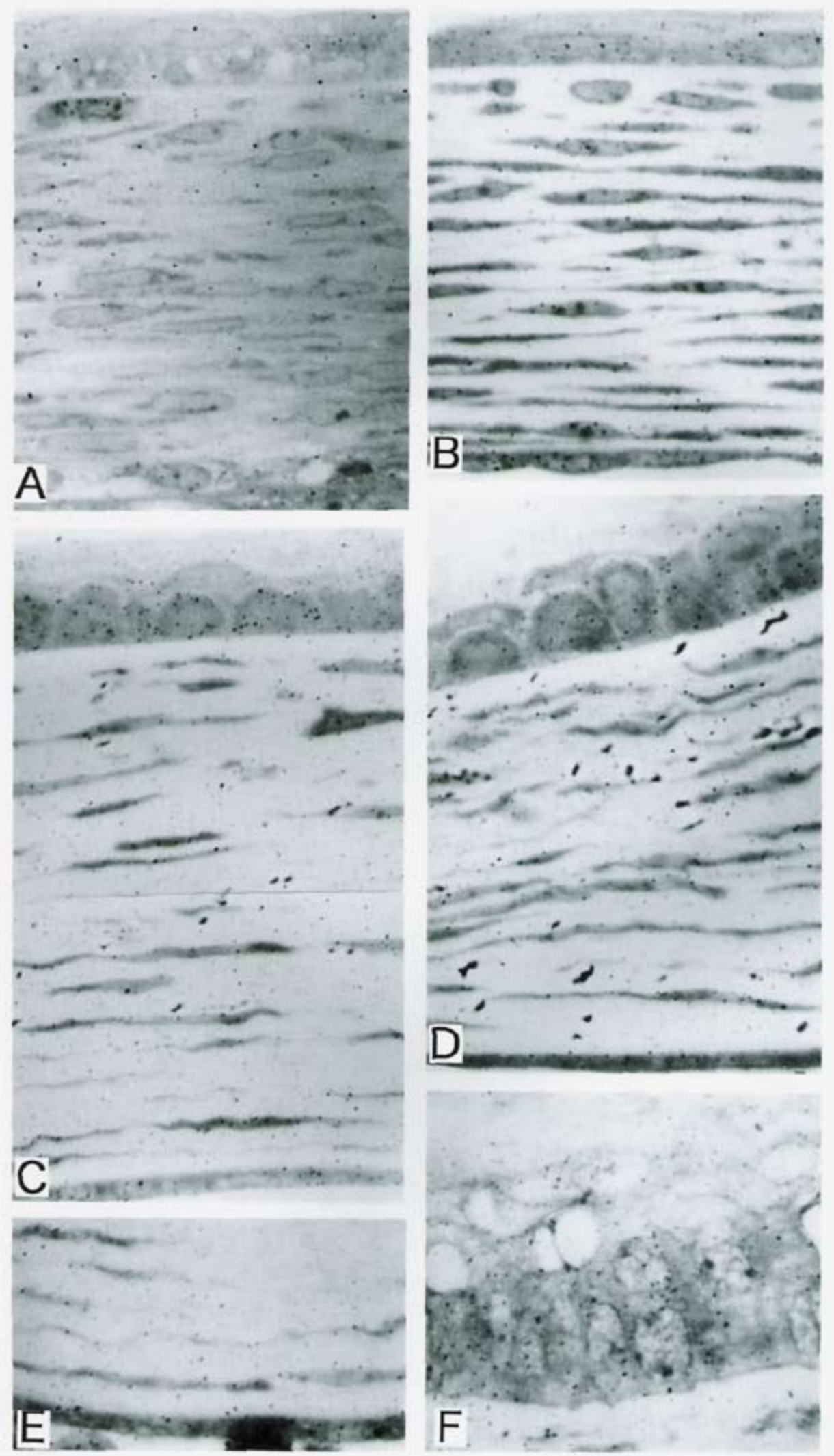

Figura 9. LMRAG of the corneas of aging mice labeled with ${ }^{3} \mathrm{H}$-leucine at various ages from embryonic day 19 to postnatal day 14, showing protein synthesis. 9A. Low power magnification LMRAG of the cornea of an embryo day 19 mouse, showing the whole layers of the cornea, the epithelium (top), the stroma (center) and the endothelium (bottom). A few silver grains can be seen over the nuclei and cytoplasm of the epithelial cells, the keratocytes and collagen fibers in the stroma as well as the endothelial cells. x1200. 9B. 9C. 9D.9E. 9F. From Cui et al. (2000) 

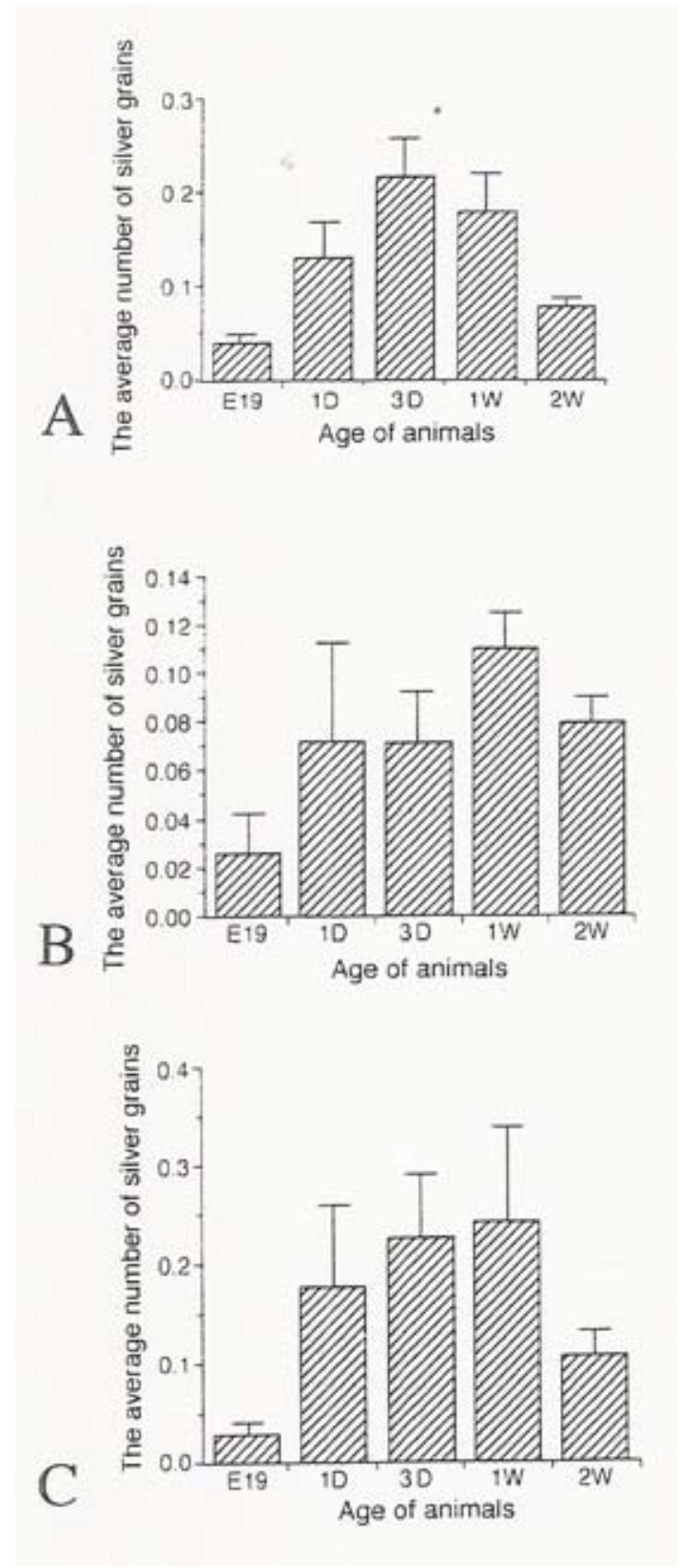

Figura 10. Histograms showing the mean numbers of silver grains per unit area $\left(100 \mu \mathrm{m}^{2}\right)$ in the epithelium $(10 \mathrm{~A})$, the stroma (10B) and the endothelium (10C) of the corneas of aging mice labeled with ${ }^{3} \mathrm{H}$-leucine at various ages showing protein synthesis. Mean \pm Standard Deviation. From Cui et al. (2000).

The collagen synthesis in the ocular tissues was also studied by the incorporation of ${ }^{3} \mathrm{H}$-proline in 4 groups of mice at various ages, from prenatal day 20, postnatal day 3, 7 and adult day 30 (Nagata, 1997c). The results showed that the sites of ${ }^{3} \mathrm{H}$-proline incorporation were located in the stromal fibroblasts in both cornea and the trabecular meshwork in the iridocorneal angle in prenatal and postnatal newborn mice (Fig. 11A,B). No silver grains were observed in the epithelial and endothelial cells. On EMRAG, silver grains were localized over the endoplasmic reticulum and Golgi apparatus of fibroblasts and over intercellular matrices consisting of collagen fibrils (Fig. 11C,D). From the quantitative analysis, numbers of silver grains were more observed in the fibroblasts in postnatal day 7 animals than younger animals at fetal day 20 and postnatal day 3, 7 and 30 (Fig. 12A). Numbers of cells per unit area showed that the cell densities increased from embryo to newborn day 3 and decreased to day 7 and 30 (Fig. 12B). In the same aging groups, the cell densities were more in the cornea than in the iridocorneal angle. It was concluded that the collagen synthetic activity was localized in the fibroblasts in the cornea and the trabecular meshwork in the iridocorneal angle in prenatal and postnatal newborn mice and the activity changed with aging, reaching the maximum at postnatal day 7 (Nagata, 1997c). 

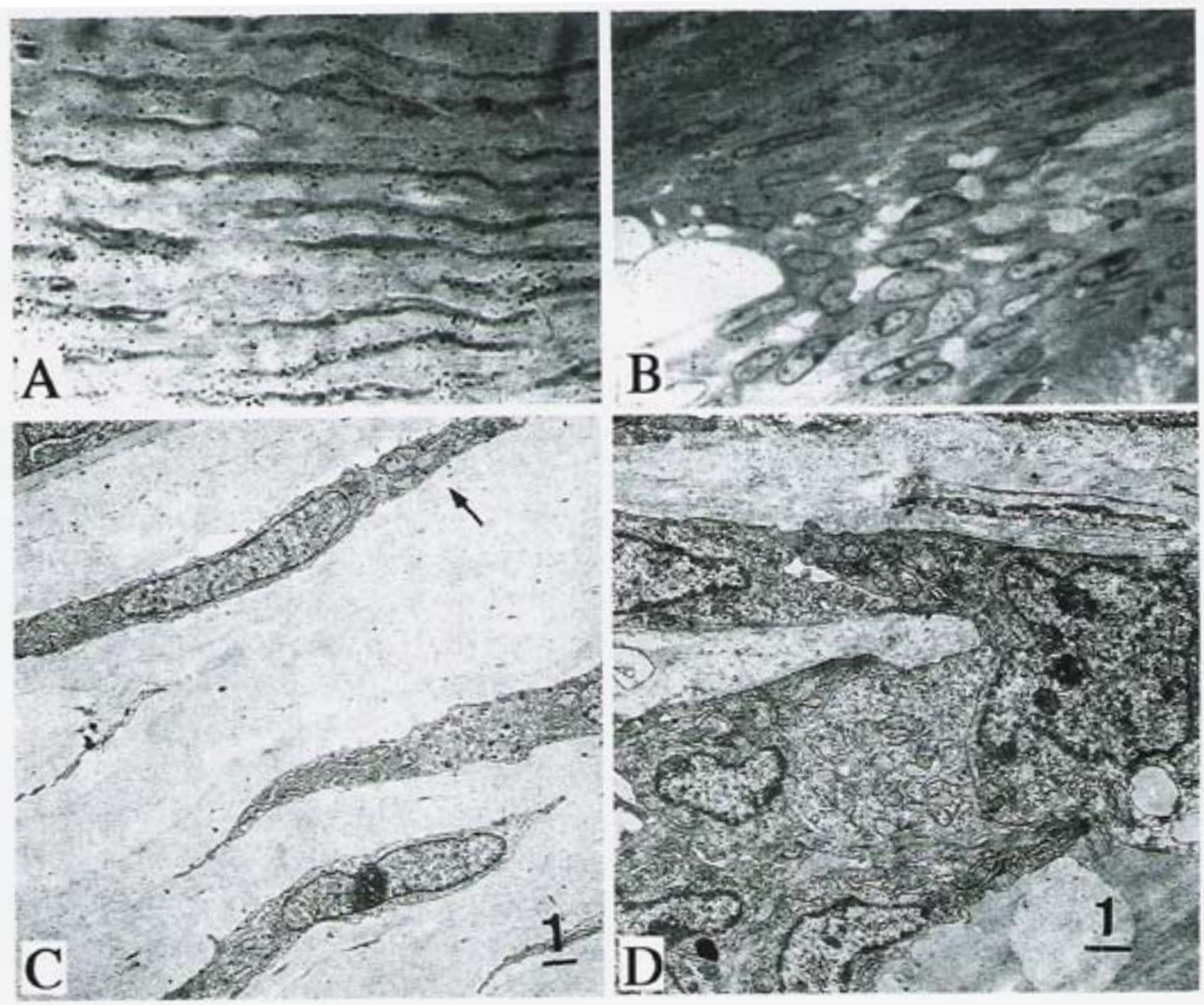

Figura 11. LM and EMRAG of the ciliary bodies of aging mice labeled with ${ }^{3} \mathrm{H}$-prolin at various ages, showing collagen synthesis. 11A. A labeled hepatocyte of a mouse at 1 month after birth. Several silver grains can be seen over the nucleolus and euchromatin in the nucleus. $x$ 6,000.11B. High power magnification of a hepatocyte of a mouse at postnatal day 14, showing a portion of a nucleolus. Many silver grains can be observed over the granular and fibrillar components of the nucleolus. x30,000. From Nagata (1997).
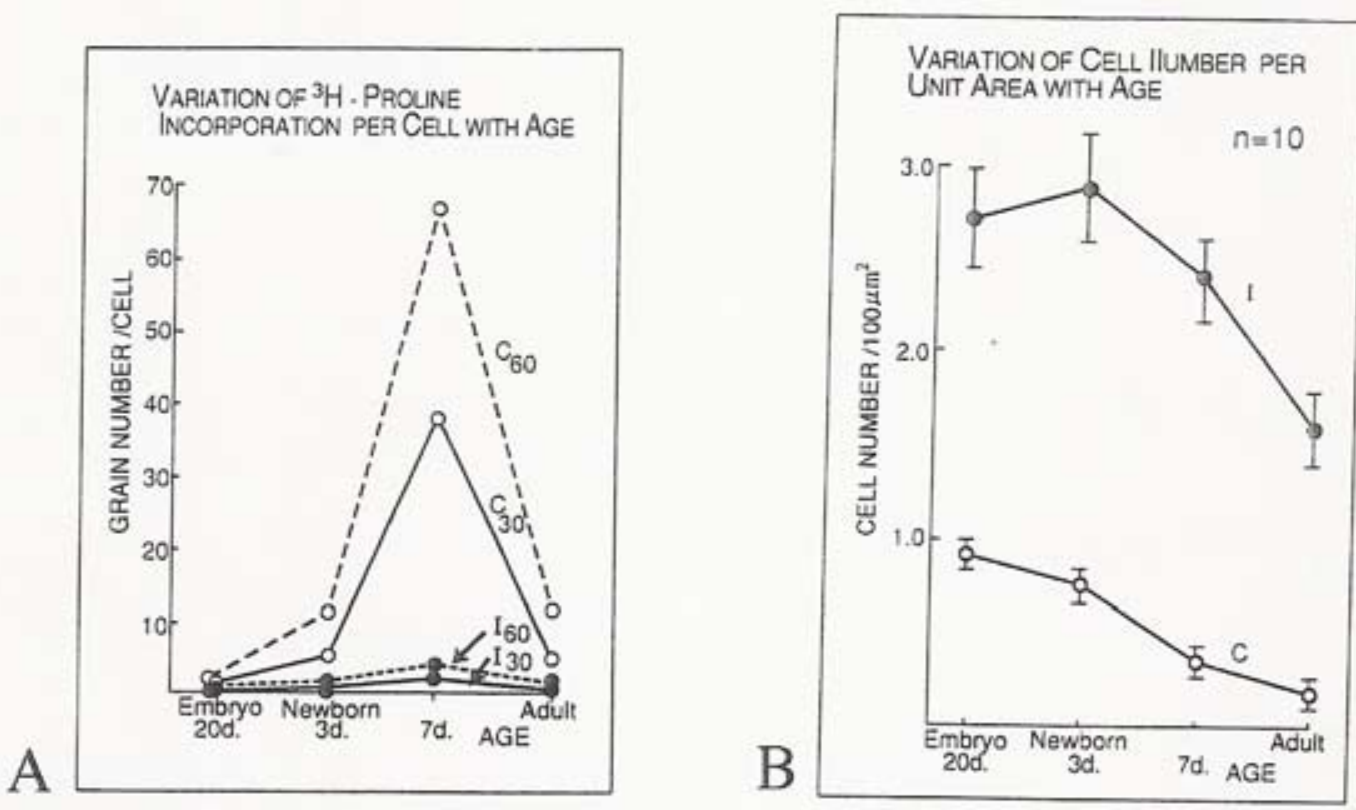

Figura 12. Transitions of grain counts and cell counts in hepatocyte nuclei of aging mice labeled with ${ }^{3} \mathrm{H}-$ proline at various ages. Mean \pm Standard Deviation. 12A. Transitional curve of mean grain counts in hepatocytes at various ages. 12B. Transitional curves of grain counts in granular components and fibrillar components of hepatocyte nucleoli at various ages. 12C. Histograms showing the ratios of grain counts in euchromatin, heterochromatin of the nuclei, granular and fibrillar components of the nucleoli in hepatocytes at various ages. From Nagata (1997). 
The glycoprotein synthesis was studied in ddY mice at various ages, from embryonic day 19 to postnatal day 1,3 , week 1, 2, and month 1 and 6 , by ${ }^{3} \mathrm{H}$-glucosamine incorporations (Nagata et al., 1995). The sites of ${ }^{3} \mathrm{H}$-glucosamine incorporations were located in the epithelial cells, stromal fibroblasts and endothelial cells from prenatal day 19 to postnatal day 1, 3, week 1, 2, and month 1, 6. No silver grains were observed in lamina limitans anterior (Bowman's membrane) and lamina limitans posterior (Descemet's membrane). The grain densities were more observed in endothelial cells of prenatal day 19 animals, but more in epithelial cells of postnatal day 1, 3 and 7 animals. From the results, it was shown that the glycoprotein synthetic activity in respective cell types in the cornea of mouse changed with aging of the animals (Nagata et al., 1995).

On the other hand, localizations of ophthalmological drugs were studied when a few beta blocking agents such as ${ }^{14} \mathrm{C}$-bupranolol (Kaken Chemical Co., Tokyo, Japan) and ${ }^{3} \mathrm{H}$-befunolol (Kaken Chemical Co., Tokyo, Japan) were instilled in albino rabbits eyes. We first studied rabbits eyes, 15 and 30 min after the instillations with ${ }^{14} \mathrm{C}$-bupranolol, by freezing the enuclated eyes quickly at liquid nitrogen temperature and cryo-sectioned in a cryostat at $-40^{\circ} \mathrm{C}$, freeze-thawed and radioautographed by light microscopic dry-mounting procedure for demonstrating soluble compounds. As the control, chemically fixed sections were wet-mounted for demonstrating insoluble compounds. The results demonstrated that the dry-mounting radioautographs showed many silver grains in the cornea, conjunctive, ciliary body, sclera and iris. The numbers of grains were quantitatively analyzed, which resulted in many silver grains in the epithelia of the conjunctive, cornea and ciliary body, while few in the stroma of the cornea, sclera, and iris at $15 \mathrm{~min}$ (Tsukahara et al., 1980). However, the silver grains decreased in the conjunctive and cornea but remarkably increased in the epithelium of the ciliary body. To the contrary, the wet-mounting radioautographs did not show any remarkable silver grains in the ocular tissues at $30 \mathrm{~min}$. It was concluded that bupranolol first penetrated into the epithelium of the conjunctiva and cornea, then moved rapidly to the ciliary body playing a role in the control of the aqueous production in the ciliary body (Tsukahara et al., 1980). We also administered ${ }^{3} \mathrm{H}$-befunolol (2-hydroxy-3-isopropylamino-proposy-benzofuran (Kaken Chemical Co., Tokyo, Japan) intravenously to pigmented rabbits, fixed the iris, ciliary body, and retina in glutaraldehyde and osmium tetroxide, embedded in epoxy resin, thin sectioned, wet-mounted for LMRAG (Yamabayashi et al., 1981; Nagata \& Yamabayashi, 1983, 1987). The results showed that silver grains were observed over the pigment granules of the iris, ciliary body, choroid and retina. It was concluded that befunolol was incorporated into the pigment granules of these cells. When the ocular tissues of White Leghorn chick embryos and adult albino ddY mice were labeled with ${ }^{3} \mathrm{H}$-befunolol in vitro, dry-mounting EMRAG revealed that many silver grains were observed over the cornea, ciliary body, iris, and retina while wet-mounting EMRAG revealed no silver grains in all the ocular tissues. Remarkable silver grains were observed to accumulate over the melanosomes of pigmented cells in the ciliary body and iris. Thus, it is supposed that soluble befunolol localized over the cornea, ciliary body and iris, but insoluble befunolol localized only on the pigmented cells. It was concluded that the betablockers bound specifically to the melanosomes of the pigmented cells in the eye (Nagata \& Yamabayashi, 1983, Nagata et al., 1987).

\subsection{The middle layer of the eyeball (Tunica media, Vascular layer or Uvea)}

The middle layer of the eyeball is designated as the vascular layer or the uvea. It consists of the iris, the ciliary body and the choroid, from anterior to posterior. The iris is an extension of the choroid and covers the lens except a round opening in the center. The ciliary body is a thick ring surrounding the lens with ciliary processes. The choroid is a vascularized coat consisting of the blood vessels and connective tissues rich in fibroblasts, melanocytes, free cells, collagen fibers and elastic fibers.

\subsubsection{The choroid}

The incorporation of ${ }^{3} \mathrm{H}$-thymidine into DNA was examined in the sclera and retina of chick embryos in early developmental stages during the period of the optic vesicle formation (day 2) to the basic layer formation (day 7) by means of LM and EM RAG. Fresh fertilized white Leghorn chicken eggs were incubated in a moist incubator at $38.5^{\circ} \mathrm{C}$ for $2,3,4$ and 7 days embryonic ages (stages 9-12, 14-20, 23-24, and 31-32 of Hamburger and Hamilton, 1951). The eyeballs were taken out and dissected in Hanks' balanced salt solution. The tissue pieces were cultured in vitro in Eagle's MEM supplemented with $10 \%$ calf serum containing ${ }^{3} \mathrm{H}$-thymidine at a concentration of $1.8 \mathrm{MBq} / \mathrm{ml}$ in a $\mathrm{CO}_{2}$ incubator for $1 \mathrm{~h}$, fixed in buffered $2.5 \%$ glutaraldehyde and $1.0 \%$ osmium teroxide, dehydrated, embedded in epoxy resin, sectioned and radioautographed. The results showed that some mesenchymal cells surrounded and 
proliferated around the optic vesicles of chick embryos forming the scleral tissues and choroid tissues from day 2 to 3, 4 and 7 (Fig. 2A,B,C). The numbers of labeled fibroblasts with ${ }^{3} \mathrm{H}$-thymidine demonstrating DNA synthesis were the highest on day 2 and decreased to day 3,4 and 7, similarly to the retinal cells (Gunarso et al., 1997). When the tissue pieces of chicken embryos were cultured in vitro in Eagle's MEM supplemented with $10 \%$ calf serum containing ${ }^{3} \mathrm{H}$-uridine at a concentration of $1.8 \mathrm{MBq} / \mathrm{ml}$ in a $\mathrm{CO}_{2}$ incubator for $1 \mathrm{~h}$, fixed in buffered $2.5 \%$ glutaraldehyde and $1.0 \%$ osmium teroxide, dehydrated, embedded in epoxy resin, sectioned and radioautographed, RNA synthesis was observed in almost all the fibroblasts in the mesenchymal cells surrounding the optic vesicles forming the scleral tissues and choroid tissues (Fig. 3A,B,C). The numbers of silver grains in the cells increased from day 2 to 3, 4 and 7, similarly to the retinal cells, showing the increase of RNA synthesis (Gunarso et al., 1996).

When the ocular tissues obtained from groups of litter ddY mice at ages varying from fetal day $9,12,14,16,19$ to postnatal day $1,3,7,14$ were labeled with ${ }^{3} \mathrm{H}$-thymidine in vitro and radioautographed, various cells in the ciliary body were also labeled (Kong et al., 1992b; Nagata et al., 1990, 1993, 1994). In the choroids, the labeled cells showing DNA synthesis were fibroblasts and pigment cells, located in the suprachoroidal layer, vessel layer and chriocapillary layer from prenatal day 19 to postnatal 1 week, but no labeled cells were observed in lamina limitans and lamina basalis (Fig. 4A,E). From postnatal day 14 to 1 year, almost no cells were labeled in all the layers (Kong et al., 1992b; Nagata et al., 1994). The labeling indices of all the cell types in the choroid were at the maximum at prenatal day 19 and decreased gradually after birth reaching 0 at postnatal day 14 (Nagata et al., 1994).

On the other hand, when the ocular tissues were labeled with ${ }^{3} \mathrm{H}$-uridine, silver grains showing RNA synthesis appeared over all cell types at all stages of development and aging (Fig. 5A,B,C,D). The grain counts in the choroid increased from prenatal day 9 to postnatal day 1 and 7 in the fibroblasts and pigment cells (Kong et al., 1992a; Kong \& Nagata, 1994; Nagata 1999a, 2000).

The protein synthesis of the ocular tissues in aging ddY mouse as revealed by ${ }^{3} \mathrm{H}$-leucine incorporation demonstrated that silver grains localized over fibroblasts and pigment cells, located in the suprachoroidal layer, vessel layer and chriocapillary layer from prenatal day 19 to early postnatal days when the outer and inner segments were formed. The peak was postnatal day 1 to 14 and the number of silver grains decreased after month 1 to year 1 (Toriyama, 1995; Nagata, 2000). The collagen synthesis in the ocular tissues was also demonstrated by the incorporation of ${ }^{3} \mathrm{H}$-proline in 4 groups of mice at various ages, from prenatal day 20, postnatal day 3, 7 and 30 (Nagata, 1997c). The results showed that the sites of ${ }^{3} \mathrm{H}$-proline incorporation were located in the stromal fibroblasts located in the suprachoroidal layer, vessel layer and chriocapillary layer from prenatal day 19 to postnatal 1 week, but no labeled cells were observed in lamina limitans and lamina basalis.

In the choroids of aging mice, the distribution and localization of TGF $\beta 1$ and $\beta F G F$, and their mRNAs, were also studied by means of in situ hybridization using ${ }^{35} \mathrm{~S}-$ labeled oligonucleotide probes (Nagata \& Kong, 1998). The results showed that mRNAs for these growth factors were synthesized in the choroidal layers from embryo to adult stages (Fig. 6). Cryosections were picked up on glass slides which were processed for in situ hybridization and radioautographed. As the results, the silver grains representing the hybridization with ${ }^{35} \mathrm{~S}$-labeled antisense oligonucleotide probe for TGF $\beta 1$ and $\beta F G F$ mRNAs mainly located in the scleral layers and some in the choroidal and pigment epithelial layers, but only background level of silver grains was found in whole retina. In the radioautograms from embryonic day 14 to adult mice ( 10 weeks), the significant distribution of silver grains represented TGF $\beta 1$ mRNA was not detected in whole retina. However, the significant silver grains were detected in scleral and choroidal layers and mesenchymal cells at E14 (Fig. 6E) and E16 (Fig. 6F), then the number of grains increased in these layers particularly in sclera from E19 to postnatal neonate (Fig. 1G) to day 14 (Fig. 1H) until adult. These results suggested that mRNAs for TGF- $\beta 1$ and $\beta F G F$ were synthesized in scleral, choroidal and pigment epithelial layers, but their proteins were transferred to the target cells of the retina and elsewhere. Furthermore, it is suggested that TGF- $\beta 1$ and $\beta F G F$ may play important roles on retinal differentiation, development and aging, in particular during the late embryonic and newborn stages. On the other hand, the distribution and localization of TGF- $\beta 1$ and $\beta$ FGF were also studied with immunocytochemical method. For immunocytochemistry, cryosections were stained with rabbit anti-TGF- $\beta 1$ and anti- $\beta$ FGF polyclonal antibodies followed by $\mathrm{ABC}$ method. The results showed that positive immunoreactivities located in the vessels of retina and choroid. By light microscopic observation, the positive immunoreactivities were located in pigment epithelial cells and the endothelial cells and wall of vessels in choroidal layers (Fig. 6A,B,C,D). The intensely positive staining was found in vessel wall of choroid and scleral layers. The negative control abolished virtually all reactivity when using the normal rabbit serum instead of 
primary antibody or using avidin-biotin-peroxidase complex solution only. The immunostaining with $\beta F G F$ antibody presented the same basal pattern as shown in TGF $\beta 1$ immunocytochemistry. The positive immunoreactivities were detected in retinal pigment epithelial layer, choroidal and scleral layers. Thus, it was suggested that TGF- $\beta 1$ and $\beta$ FGF may play important roles on retinal differentiation, development and aging, in particular during the late embryonic and newborn stages (Nagata \& Kong, 1998).

The localization of a beta-blocking agent (Kaken Co., Tokyo, Japan) was studied by LM and EMRAG (Yamabayashi et al., 1981; Nagata \& Yamabayashi, 1983). The ocular tissues of chickens were taken out, cut into small pieces and labeled with ${ }^{3} \mathrm{H}$-befunolol in Eagle's MEM $(3.7 \mathrm{MBq} / \mathrm{ml})$ in a $\mathrm{CO}_{2}$ incubator for 30 to $60 \mathrm{~min}$. The tissues were cryo-fixed in liquid nitrogen and some of them were dry-sectioned, some were freeze-dried or freeze-substituted and embedded in Epon, dry-sectioned and dry-mounted. Some other tissues were chemically fixed, embedded and wet-mounted. Dry-mounting EM radioautograms revealed that many silver grains were found over the melanosomes of the pigmented cells in the choroid demonstrating soluble compounds. On the contrary, only few silver grains were found over the melonosomes of the pigmented cells by conventional wet-mounting EMRAG. From the results, it was found that soluble ${ }^{3} \mathrm{H}$-befunolol was accumulated specifically over the melanosomes of the pigmented cells in the choroid, but not in the retina proper (Nagata \& Yamabayashi, 1983, Nagata et al., 1987, 1988)

\subsubsection{The Ciliary body}

When the ocular tissues obtained from groups of litter ddY mice at ages varying from fetal day 19 to postnatal day $1,3,7,14$, and month $1,2,6$ were injected intraperitoneally with ${ }^{3} \mathrm{H}$-thymidine and radioautographed, DNA synthesis in the cilliary bodies of mice were observed (Kong et al., 1992b; Nagata et al., 1990, 1993, 1994). In the ciliary bodies, from corona ciliaris and orbiculus ciliaris, the labeled cells showing silver grains were located in the ciliary epithelial cells, pigment epithelial cells, stromal cells and smooth muscle cells from prenatal day 19 to postnatal 1 week, but no labeled cells were observed in any cell types from postnatal day 14 to month 1, 2, 6, and year 1 (Kong et al., 1992b; Nagata et al., 1990, 1993, 1994). The labeling indices of all the cell types in the ciliary body were at the maximum at prenatal day 19 and decreased gradually after birth reaching 0 at postnatal day 14 (Nagata et al., 1994; Nagata, 2000).

On the other hand, when the ocular tissues were labeled with ${ }^{3} \mathrm{H}$-uridine, silver grains showing RNA synthesis appeared over all the cell types, in both nuclei and cytoplasm, at all stages of development and aging (Kong et al., 1992a; Nagata et al., 1991, 1992). The grain counts in the ciliary bodies increased from prenatal day 9 to postnatal day 1 and 7 in the fibroblasts (Kong et al., 1992a; Kong \& Nagata, 1994; Nagata, 1999a, 2000).

The protein synthesis of the ocular tissues in aging ddY mouse as revealed by ${ }^{3} \mathrm{H}-$ leucine incorporation demonstrated that silver grains localized over all the cell types, in the ciliary epithelial cells, pigment epithelial cells, stromal cells and smooth muscle cells from prenatal to early postnatal days. The peak was postnatal day 1 to 14 and the number of silver grains decreased after month 1 to year 1 (Toriyama, 1995; Nagata, 2000). The collagen synthesis in the ocular tissues was also demonstrated by the incorporation of ${ }^{3} \mathrm{H}$-proline in 4 groups of mice at various ages, from prenatal day 20 , postnatal day 3, 7 and 30 (Nagata, 1997c). The results showed that the sites of ${ }^{3} \mathrm{H}$-proline incorporation were over all the cell types, in the ciliary epithelial cells, pigment epithelial cells, stromal cells and smooth muscle cells from prenatal to early postnatal days. The peak was postnatal day 1 to 14 and the number of silver grains decreased after month 1 to year 1 (Toriyama, 1995; Nagata, 2000).

On the other hand, localizations of ophthalmological drugs in the ciliary bodies were also studied when a few beta blocking agents such as ${ }^{14} \mathrm{C}$-bupranolol (Kaken Chemical Co., Tokyo, Japan), ${ }^{3} \mathrm{H}$-befunolol (Kaken Chemical Co., Tokyo, Japan) and ${ }^{3} \mathrm{H}$-dihydroalprenolol (Amersham International, Amersham, UK) were administered. The results were described in the sections of the cornea and choroid. Both ${ }^{14} \mathrm{C}-$ bupranolol and ${ }^{3} \mathrm{H}$-befunolol were localized in the ciliary bodies of rabbits and chickens after instillations $\left({ }^{14} \mathrm{C}\right.$-bupranolol), intravenous injections $\left({ }^{3} \mathrm{H}\right.$-befunolol) or in vitro incubations ( ${ }^{3} \mathrm{H}$-dihydroalprenolol). When the ocular tissues of White Leghorn chick embryos and adult albino ddY mice were labeled with ${ }^{3} \mathrm{H}$-befunolol or ${ }^{3} \mathrm{H}$-dihydroalprenolol in vitro, dry-mounting EMRAG revealed that much more silver grains were observed in the ciliary bodies to accumulate over the melanosomes of pigmented cells in the ciliary body and iris than conventional wet-mounting EMRAG (Nagata \& Yamabayashi, 1983; Nagata et al., 1987, 1988). It was concluded that the beta-blockers bound specifically to the melanosomes of the ciliary bodies in the eyes. 


\subsubsection{The iris}

When the ocular tissues obtained from groups of litter ddY mice at ages varying from fetal day $9,12,14,16,19$ to postnatal day $1,3,7,14$ were labeled with ${ }^{3} \mathrm{H}$-thymidine in vitro and radioautographed, various cells in the iris were also labeled (Kong et al., 1992b, Nagata et al., 1990, 1993, 1994). In the iris, the labeled cells were located in all the 3 layers of the iris, the endothelium, the stroma containing smooth muscles and the pigment layer from prenatal day 19 to postnatal 1 week, but no labeled cells were observed in any cell types from postnatal day 14 to 1 year (Kong et al., 1992b; Nagata et al., 1994). The labeling indices of all the cell types in the iris were the maximum at prenatal day 19 and decreased gradually after birth reaching 0 at postnatal day 14 (Nagata et al., 1994).

On the other hand, when the ocular tissues were labeled with ${ }^{3} \mathrm{H}$-uridine, silver grains appeared over all the cell types in the 3 layers, the endothelium, the stroma and the pigment layer, in both nuclei and cytoplasm, at all stages of development and aging (Kong et al., 1992a; Nagata et al., 1990, 1993, 1994). The grain counts in the iris increased from prenatal day 9 to postnatal day 1 and 7 in the fibroblasts (Kong et al., 1992a; Kong \& Nagata, 1994; Nagata, 1999c).

The protein synthesis of the ocular tissues in aging ddY mouse as revealed by ${ }^{3} \mathrm{H}-$ leucine incorporation demonstrated that silver grains localized over all the cell types in the 3 layers, the endothelium, the stroma and the pigment layer, in both nuclei and cytoplasm, at all stages of development and aging. The peak was postnatal day 1 to 7 and the number of silver grains decreased after day 14 to year 1 (Toriyama, 1995; Nagata, 2000). The collagen synthesis in the ocular tissues was also demonstrated by the incorporation of ${ }^{3} \mathrm{H}$-proline in 4 groups of mice at various ages, from prenatal day 20, postnatal day 3, 7 and 30 (Nagata, 1997c). The results showed that the sites of ${ }^{3} \mathrm{H}$-proline incorporation were located in the stromal fibroblasts in the iris in prenatal and postnatal newborn mice. No silver grains were observed in the epithelial and endothelial cells. The number of silver grains per cell increased from embryo to newborn day 3 , reached the maximum on day 7 , then decreased to adult postnatal day 30 . The cell densities decreased from embryo day 20 to newborn day 3, 7 and 30 (Nagata, 1997c).

On the other hand, localizations of ophthalmological drugs in the iris tissues were also studied when a few beta blocking agents such as ${ }^{14} \mathrm{C}$-bupranolol, ${ }^{3} \mathrm{H}$-befunolol and ${ }^{3} \mathrm{H}$-dihydroalprenolol were administered. The results were described in the sections of the cornea and ciliary body. Both ${ }^{14} \mathrm{C}$-bupranolol and ${ }^{3} \mathrm{H}$-befunolol were localized in the ciliary bodies and iris of rabbits and chickens after instillations $\left({ }^{14} \mathrm{C}\right.$-bupranolol), intravenous injections $\left({ }^{3} \mathrm{H}\right.$-befunolol) or in vitro incubations $\left({ }^{3} \mathrm{H}\right.$-dihydroalprenolol). When the ocular tissues of White Leghorn chick embryos and adult albino ddY mice were labeled with ${ }^{3} \mathrm{H}$-befunolol or ${ }^{3} \mathrm{H}$-dihydroalprenolol in vitro, dry-mounting EMRAG revealed that much more silver grains were observed in the iris to be accumulated over the melanosomes of pigmented cells in the iris tissues than conventional wet-mounting EMRAG (Nagata \& Yamabayashi, 1983; Nagata et al., 1987, 1988). It was concluded that the beta-blockers bound specifically to the melanosomes of the pigmented cells of the iris in the eyes.

\subsection{The internal layer of the eyeball (Tunica interna or Retina)}

The internal layer of the eyeball, Tunica interna, consists of 2 layers, the outer layer is the pigment epithelium and the inner layer is the retina proper. The retina proper consists of 2 portions; the anterior portion is not photosensitive and constitutes the inner lining of the ciliary body and the iris, while the posterior portion is photosensitive.

\subsubsection{The pigment epithelium}

The outer layer of the internal layer of the eyeball or Tunica interna is called the pigment epithelium, while the inner layer of Tunica interna is the retina proper. We first studied the nucleic acid synthesis, both DNA and RNA, in the ocular tissues of white Leghorn chick embryos from incubation day 1 to day 14 by LM and EMRAG (Gunarso 1984a,b; Gunarso et al. 1996, 1997). The patterns of localization of labeled cells and average grain counts were compared in the anterior, equatorial and posterior regions of the retina. It was shown that the labeled cells with silver grains due to ${ }^{3} \mathrm{H}$-thymidine demonstrating DNA synthesis were most frequently observed in the nuclei of the pigment epithelial cells in the posterior region of the day 2 chick embryo optic vesicle (Fig. 2A,B,C). On day 3, most labeled cells were found in the anterior region and decreased in the posterior region. The numbers of labeled cells were more in the posterior regions than the anterior and the equatorial regions. On the other hand, the silver grains incorporating ${ }^{3} \mathrm{H}$-uridine due to RNA synthesis were observed over all the pigment cells 

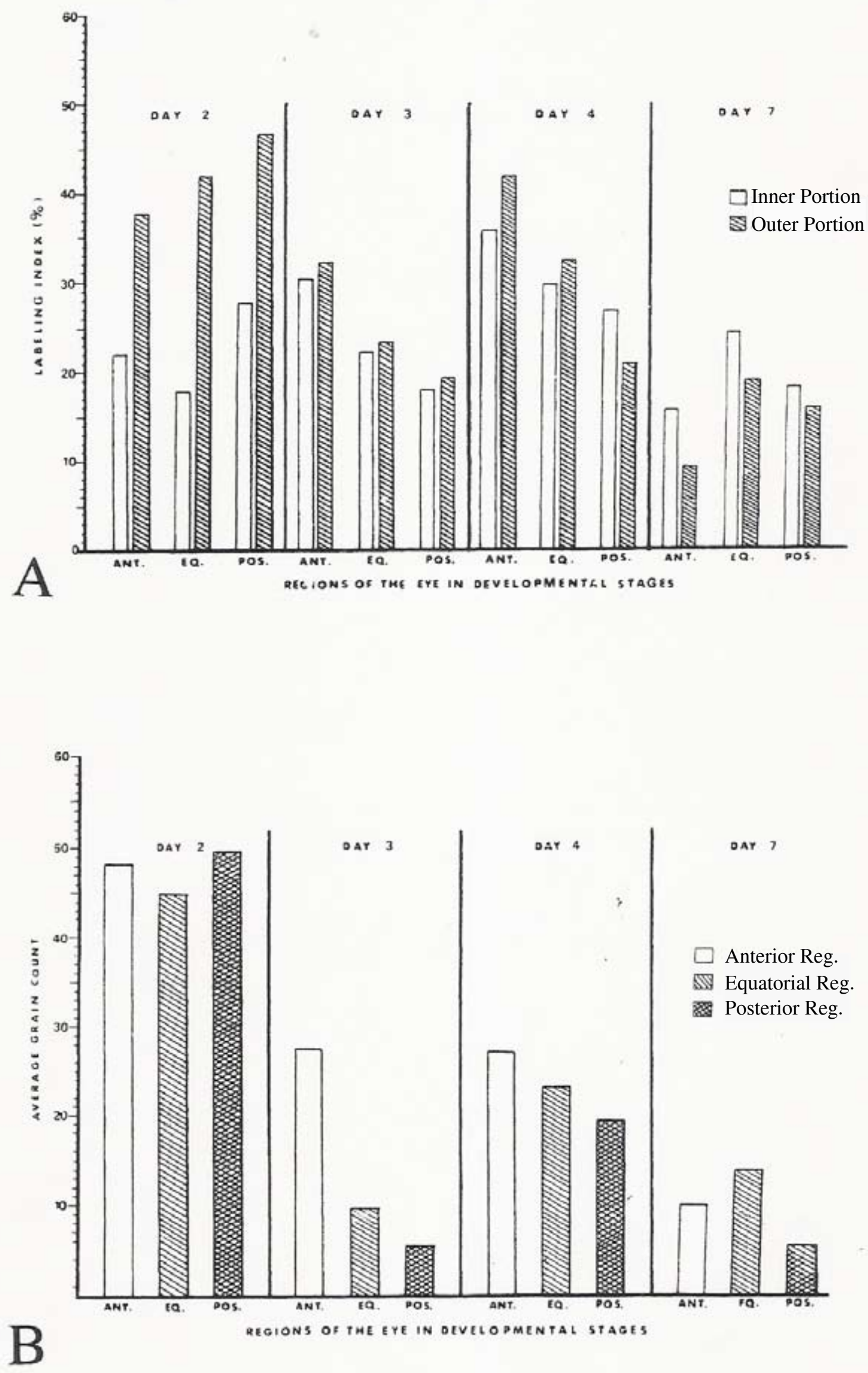

Figura 13. Histogram of labeling indices (A) and average grain counts (B) in anterior (ANT), equatorial (EQ) and posterior (POS) regions of chick embryo retinas labeled with ${ }^{3} \mathrm{H}$-thymidine at various stages from incubation day 2, 3, 4 and 7. From Gunarso et al. (1997). 
which increased from day 1 to day 7 and it was more in the anterior region than in the posterior region (Gunarso et al., 1996).

Then, DNA and RNA syntheses in the ocular tissues of aging mice were also studied (Gao et al., 1992a,b, 1993; Kong, 1993; Kong et al., 1992a,b; Kong \& Nagata, 1994). The ocular tissues obtained from groups of litter ddY mice at ages varying from fetal day $9,12,14,16,19$ to postnatal day $1,3,7,14$ were labeled with ${ }^{3} \mathrm{H}$-thymidine in vitro and radioautographed (Gao et al., 1992a,b). Some of the nuclei in the pigment epithelial cells were labeled with silver grains showing DNA synthesis (Fig. 4A,E). The labeling indices of pigment epithelial cells were higher in earlier stages than in later stages, during which they steadily declined. However, pigment epithelium followed different courses from the retina in their changes of labeling indices during embryonic development. In the pigment epithelium, the labeling indices gradually increased in the anterior region, but decreased in the equatorial and the posterior regions through all the developmental stages. These results suggest that the proliferation of both the retina and pigment epithelium in the central region occurred earlier than those of the peripheral regions (Gao et al., 1992a,b).

On the other hand, the silver grains due to incorporations of ${ }^{3} \mathrm{H}$-uridine synthesizing RNA were observed over the nuclei and cytoplasm of all retinal cells and pigment cells of the chick embryos from day 2 to 7 (Fig. 2A,B,C). The number of silver grains incorporating ${ }^{3} \mathrm{H}$-uridine increased from day 1 to day 7 and it was more in the anterior regions than in the posterior regions at the same stage (Gunarso et al., 1996). Then, RNA syntheses in the ocular tissues of aging ddY mice were also studied (Fig. 5A,B,C,D). When the ocular tissues of mice were labeled with ${ }^{3} \mathrm{H}$-uridine, silver grains appeared over all pigment cells at all stages of development and aging (Kong et al., 1992b). The grain counts in the retina and the pigment epithelium increased from prenatal day 9 to postnatal day 1 in the retinal cells, while they increased from prenatal day 12 to postnatal day 7 in the pigment epithelial cells (Kong et al., 1992a; Kong \& Nagata, 1994).

The protein synthesis of the pigment epithelium in aging ddY mouse as revealed by ${ }^{3} \mathrm{H}$-leucine incorporation demonstrated that numbers of silver grains in pigment cells increased from embryonic day 19 and early postnatal days, then decreased to year 1 (Toriyama, 1995). The peak was day 1 after birth to day 7 and decreased from day 14 to month 6 to 12 (year 1).

The localization of a beta-blocking agent (Kaken Co., Tokyo, Japan), befunolol labeled with ${ }^{3} \mathrm{H}$, in the pigment epithelium was also studied (Yamabayashi et al., 1981; Nagata \& Yamabayashi, 1983; Nagata et al., 1987, 1988). The ocular tissues of chickens were taken out, cut into small pieces and labeled with ${ }^{3} \mathrm{H}$-befunolol in Eagle's MEM $(3.7 \mathrm{MBq} / \mathrm{ml})$ in a $\mathrm{CO}_{2}$ incubator for 30 to $60 \mathrm{~min}$. The tissues were cryo-fixed in liquid nitrogen and some of them were dry-sectioned, some were freeze-dried or freeze-substituted and embedded in Epon, dry-sectioned and dry-mounted. Some other tissues were chemically fixed, embedded and wet-mounted. Dry-mounting EM radioautograms revealed that many silver grains were found over the melanosomes of the pigmented cells demonstrating soluble compounds. On the contrary, only few silver grains were found over the melonosomes of the pigmented cells of the iris and the cilliary bodies by conventional wet-mounting EMRAG. From the results, it was found that soluble ${ }^{3} \mathrm{H}$-befunolol was accumulated specifically over the melanosomes of the pigmented cells, which correlated well with the clinical findings (Nagata \& Yamabayashi, 1983; Nagata et al., 1987, 1988)

\subsubsection{The retina proper}

The retina proper consists of 2 portions; the anterior portion is not photosensitive and constitutes the inner lining of the ciliary body and the iris, while the posterior portion is photosensitive. We first studied the nucleic acid synthesis, both DNA and RNA, in the ocular tissues of white Leghorn chick embryos from incubation day 1 to day 14 by LM and EMRAG (Gunarso, 1984a,b; Gunarso et al., 1996, 1997). The patterns of localization of labeled cells and average grain counts were compared in the anterior, equatorial and posterior regions of the retina. It was shown that the labeled cells with silver grains due to ${ }^{3} \mathrm{H}$-thymidine demonstrating DNA synthesis were most frequently observed in the nuclei of the retinal cells in the posterior region of the day 2 chick embryo optic vesicle (Fig. 13A,B) and the labeled cells moved from anterior to posterior regions. On day 3, most labeled cells were found in the anterior region and decreased in the posterior region. The number of labeled cells as expressed by labeling index, was more in the posterior regions than the anterior and the equatorial regions and more in the outer portions than in the inner portions at day 2, but the labeling index became more in the anterior regions than the equatorial and posterior regions at day 3,4 and 7 and it became more in the inner portions than in the outer portions at day 7, decreasing from day 2 to 3, 4 and 7 in each regions (Fig. 13A,B). By EMRAG, 
we found DNA synthesis not only in the nuclei but also in mitochondria in cytoplasm (Gunarso, 1984b; Gunarso et al., 1996). The nucleic acid synthesis in mitochondria, both DNA and RNA syntheses, were later found in other cells such as adrenal cells (Ito \& Nagata, 1996; Nagata et al., 2000) or hepatocytes (Nagata \& Ma, 2005a,b).

\subsubsection{The retina proper}

The retina proper consists of 2 portions; the anterior portion is not photosensitive and constitutes the inner lining of the ciliary body and the iris, while the posterior portion is photosensitive. We first studied the nucleic acid synthesis, both DNA and RNA, in the ocular tissues of white Leghorn chick embryos from incubation day 1 to day 14 by LM and EMRAG (Gunarso, 1984a,b; Gunarso et al., 1996, 1997). The patterns of localization of labeled cells and average grain counts were compared in the anterior, equatorial and posterior regions of the retina. It was shown that the labeled cells with silver grains due to $3 \mathrm{H}$-thymidine demonstrating DNA synthesis were most frequently observed in the nuclei of the retinal cells in the posterior region of the day 2 chick embryo optic vesicle (Fig. 13A,B) and the labeled cells moved from anterior to posterior regions. On day 3, most labeled cells were found in the anterior region and decreased in the posterior region. The number of labeled cells as expressed by labeling index, was more in the posterior regions than the anterior and the equatorial regions and more in the outer portions than in the inner portions at day 2, but the labeling index became more in the anterior regions than the equatorial and posterior regions at day 3,4 and 7 and it became more in the inner portions than in the outer portions at day 7, decreasing from day 2 to 3, 4 and 7 in each regions (Fig. 13A,B). By EMRAG, we found DNA synthesis not only in the nuclei but also in mitochondria in cytoplasm (Gunarso 1984b; Gunarso et al., 1996). The nucleic acid synthesis in mitochondria, both DNA and RNA syntheses, were later found in other cells such as adrenal cells (Ito and Nagata 1996 ; Nagata et al., 2000) or hepatocytes (Nagata and Ma, 2005a,b).

On the other hand, silver grains due to RNA synthesis were found in both nuclei and cytoplasm (Fig. 2). The number of silver grains incorporating ${ }^{3} \mathrm{H}$-uridine due to RNA synthesis increased from day 1 to day 7 and it was more in the anterior region than in the posterior region (Gunarso, 1984a,b; Gunarso et al., 1996).

Then, DNA and RNA syntheses in the ocular tissues of aging mice were also studied (Gao et al., 1992a,b, 1993; Kong, 1993; Kong et al., 1992a,b; Kong \& Nagata, 1994). The ocular tissues obtained from groups of litter ddY mice at ages varying from fetal day 9, 12, 14, 16, 19 to postnatal day 1, 3, 7, 14 were labeled with ${ }^{3} \mathrm{H}$-thymidine in vitro and radioautographed (Gao et al., 1992a,b). The labeling indices of retina and pigment epithelium were higher in earlier stages than in later stages, during which they steadily declined (Fig. 14). However, the retina and pigment epithelium followed different courses in their changes of labeling indices during embryonic development. In the retina, the labeling indices in the vitreal portions were more than those in the scleral portions during the earlier stages. However, the indices of scleral portions were more than those in the vitreal portions in the later stages (Fig. 15). Comparing the three regions of the retina of mouse, anterior, equatorial and posterior, the labeling indices of the anterior regions were generally higher than those of the equatorial and posterior regions (Fig. 14A). In the pigment epithelium (Fig. 14B), the labeling indices gradually increased in the anterior region, but decreased in the equatorial and the posterior regions through all the developmental stages. These results suggest that the proliferation of both the retina and pigment epithelium in the central region occurred earlier than those of the peripheral regions (Gao et al., 1992a,b). In the juvenile and adult stages, however, the labeled cells were localized at the middle of the bipolar-photoreceptor layer of the retina, where was supposed to be the undifferentiated zone (Kong, 1993; Kong et al., 1992a; Nagata, 1999a). The difference between the chicken and mice was that in chicken the labeled cells with ${ }^{3} \mathrm{H}$-thymidine due to DNA synthesis were most frequently observed in the nuclei of the retinal cells in the posterior region in early stage at day 2 chick embryo but the labeled cells later moved from posterior to anterior regions and most labeled cells were found in the anterior region on day 3,4 and 7, while in mice the labeling indices were higher in the anterior region and lower in the equatorial and the posterior regions through all the developmental stages. Thus, it is supposed that the retinal cells in chicken first proliferated mainly in the anterior regions and later in the equatorial and posterior regions in contrast that they proliferated mainly in the equatorial and posterior regions through all the developmental stages. 

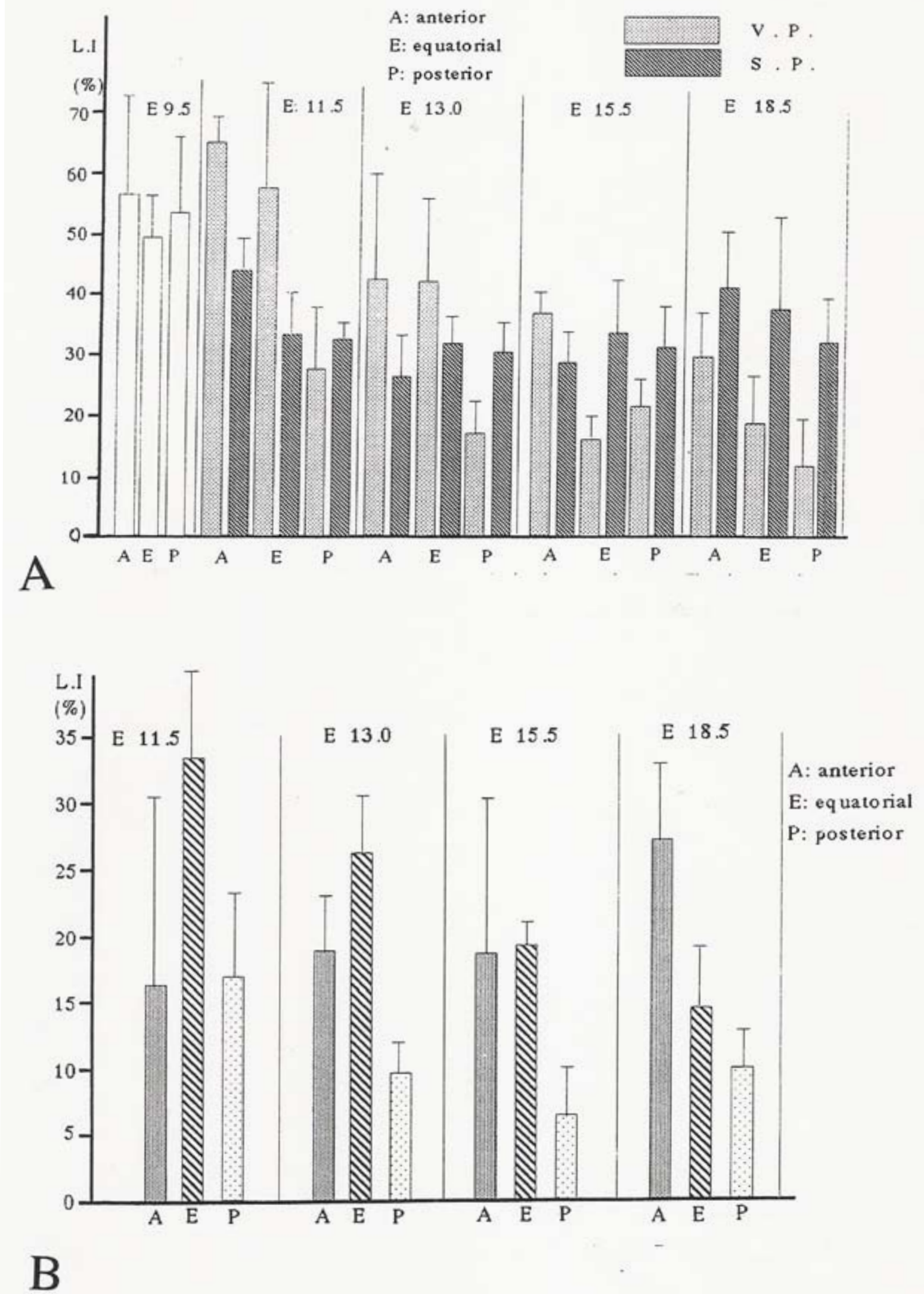

Figura 14. Histograms showing the labeling indices of retinal cells (A) and pigment epithelial cells (B) in the 3 regions of the eye germs, anterior, equatorial and posterior regions, of mice labeled with ${ }^{3} \mathrm{H}$-thymidine during embryonic developmental stages. The retina was divided into 2 portions, the vitreal portion (V.P.) and the scleral portion (S.P.) from the middle line. Mean \pm Standard Deviation. From Kong et al. (1992a). 
On the other hand, the silver grains due to incorporations of ${ }^{3} \mathrm{H}$-uridine synthesizing RNA were observed over the nuclei and cytoplasm of all retinal cells of the chick embryos from day 2 to 7 (Figs. 3, 16). The number of silver grains incorporating ${ }^{3} \mathrm{H}$-uridine increased from day 1 to day 7 and it was more in the anterior regions than in the posterior regions at the same stage (Gunarso et al., 1996). Then, RNA syntheses in the ocular tissues of aging ddY mice were also studied (Fig. 5). When the ocular tissues of mice were labeled with ${ }^{3} \mathrm{H}$-uridine (Fig. 17), silver grains appeared over all cell types at all stages of development and aging (Kong et al., 1992b). The grain counts in the retina and the pigment epithelium increased from prenatal day 9 to postnatal day 1 in the retinal cells, while they increased from prenatal day 12 to postnatal day 7 in the pigment epithelial cells (Kong et al., 1992a; Kong \& Nagata, 1994).

The protein synthesis of the retina in aging ddY mouse as revealed by ${ }^{3} \mathrm{H}$-leucine incorporation demonstrated that number of silver grains in bipolar cells and photoreceptor cells was most intense at embryonic day 19 and early postnatal days when the outer and inner segments were formed. The peak was 1 day after birth and decreased from 14 days to 1 year after birth. The grain counts were more in the photoreceptor cells than in the bipolar cells at every stage from embryo to postnatal days (Toriyama, 1995; Nagata, 2000).

The distribution and localization of TGF- $\beta 1$ and $\beta F G F$, and their mRNAs in the ocular tissues of aging mice were also studied (Nagata \& Kong, 1998). The posterior segments of BALB/c mouse eyes, from embryonic day 14, 16, 19, and postnatal day 1, 3, 5, 7, 14, 28, 42 and 70 were used as materials. For in situ hybridization, ${ }^{35} \mathrm{~S}$-labeled oligonucleotide probes for TGF- $\beta 1$ and $\beta F G F$ were used to detect their mRNAs (Fig. 6). Cryosections were picked up on glass slides which were processed for in situ hybridization and radioautographed. As the results the silver grains, represented the hybridization with ${ }^{35}$ S-labeled antisense oligonucleotide probe for TGF $\beta 1$ and $\beta$ FGF mRNAs, mainly located in the scleral layers and some in the choroidal and pigment epithelial layers as described in each section, but only background level of silver grains was found in whole retina. In the radioautograms from embryonic day 14 to adult mice (10 weeks), the significant distribution of silver grains represented TGF $\beta 1$ mRNA was not detected in whole retina. However, the significant silver grains were detected in scleral and choroidal layers and mesenchymal cells at E14 (Fig. 6D) and E16, then the number of grains increased in these layers particularly in sclera from E19 to postnatal neonate (Fig. 6E) until adult. These results suggested that mRNAs for TGF- $\beta 1$ and $\beta$ FGF were synthesized in scleral, choroidal and pigment epithelial layers, but their proteins were transferred to the target cells of the retina. Furthermore, it is suggested that TGF$\beta 1$ and $\beta F G F$ may play important roles on retinal differentiation, development and aging, in particular during the late embryonic and newborn stages (Nagata \& Kong, 1998).

On the other hand, the distribution and localization of TGF- $\beta 1$ and $\beta$ FGF were also studied with immunocytochemical method (Nagata \& Kong, 1998). The posterior segments of BALB/c mouse eyes, from embryonic day 14, 16, 19, and postnatal day $1,3,5,7,14,28,42$ and 70 the same materials as the in situ hybridization were used. For immunocytochemistry, cryosections were stained with rabbit anti-TGF- $\beta 1$ and anti- $\beta$ FGF polyclonal antibodies followed by ABC method. The results showed that positive immunoreactivities located in ganglion cell layers, and the vessels of retina and choroid. By light microscopic observation, the positive immunoreactivities were located in ganglion cell layers, inner and outer plexiform layers, cytoplasm of pigment epithelial cells, scleral layers, and the endothelial cells and wall of vessels in retinal and choroidal layers. The inner and outer nuclear layers and segments of photoreceptors did not show any immunoreactivity. The intensely positive staining was found in vessel wall of choroid and scleral layers, and ganglion cells but not glial cells of ganglion cell layer. The negative control abolished virtually all reactivity when using the normal rabbit serum instead of primary antibody or using avidin-biotin-peroxidase complex solution only. The immunostaining with $\beta F G F$ antibody presented the same basal pattern as shown in TGF $\beta 1$ immunocytochemistry (Nagata \& Kong, 1998). The positive immunoreactivities were detected in ganglion cell layer, inner and outer plexiform layers, retinal pigment epithelial layer, choroidal and scleral layers.

On the other hand, the distributions of some of the ophthalmological drugs used for the treatment of glaucoma patients were examined in the ocular tissues. Bupranolol is a beta-blocking agent widely used for glaucoma as the eye drop in USA and Japan (Tsukahara et al., 1980). 14C-bupranolol (Kaken Co., Tokyo, Japan) was experimentally instilled into the eyes of white rabbits and the ocular tissues were enucleated after 15 and $30 \mathrm{~min}$, which were cryo-fixed in liquid nitrogen and the frozen tissues were cryosectioned and either freeze-dried or thaw-mounted onto glass slides, followed by either dry-mounting or wet-mounting LMRAG. The results showed that silver grains by dry-mounting RAG appeared intensely in the conjunctival and corneal epithelia at 15 minutes, then they decreased there and increased in the 

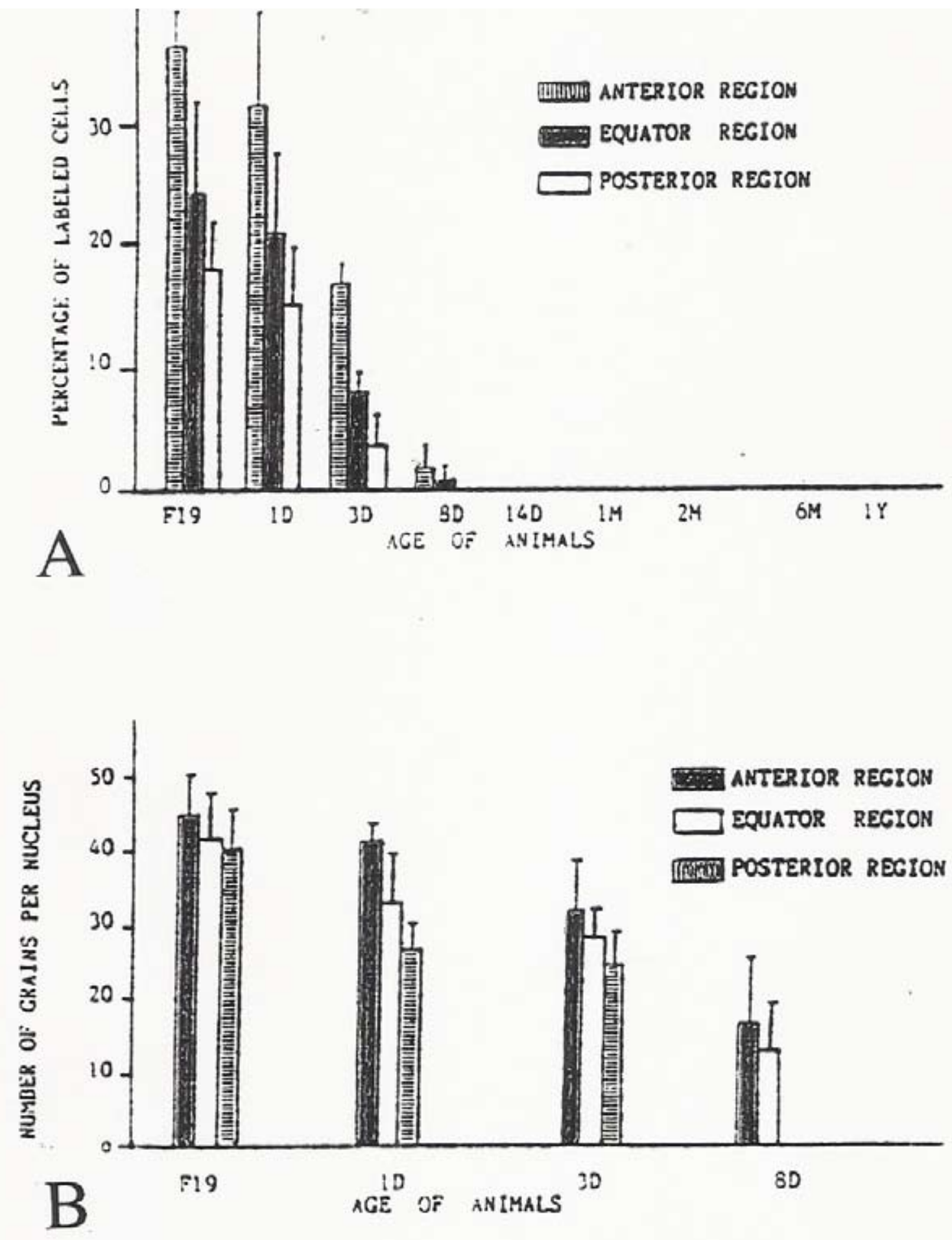

Figura 15. Histograms showing the labeling indices (15A) and grain counts (15B) of retinal cells in the 3 regions of the eyes, anterior (A), equatorial (E) and posterior (P) regions, of mice labeled with ${ }^{3} \mathrm{H}$-thymidine during postnatal developmental stages. Mean \pm Standard Deviation. From Gao et al. (1992b). 


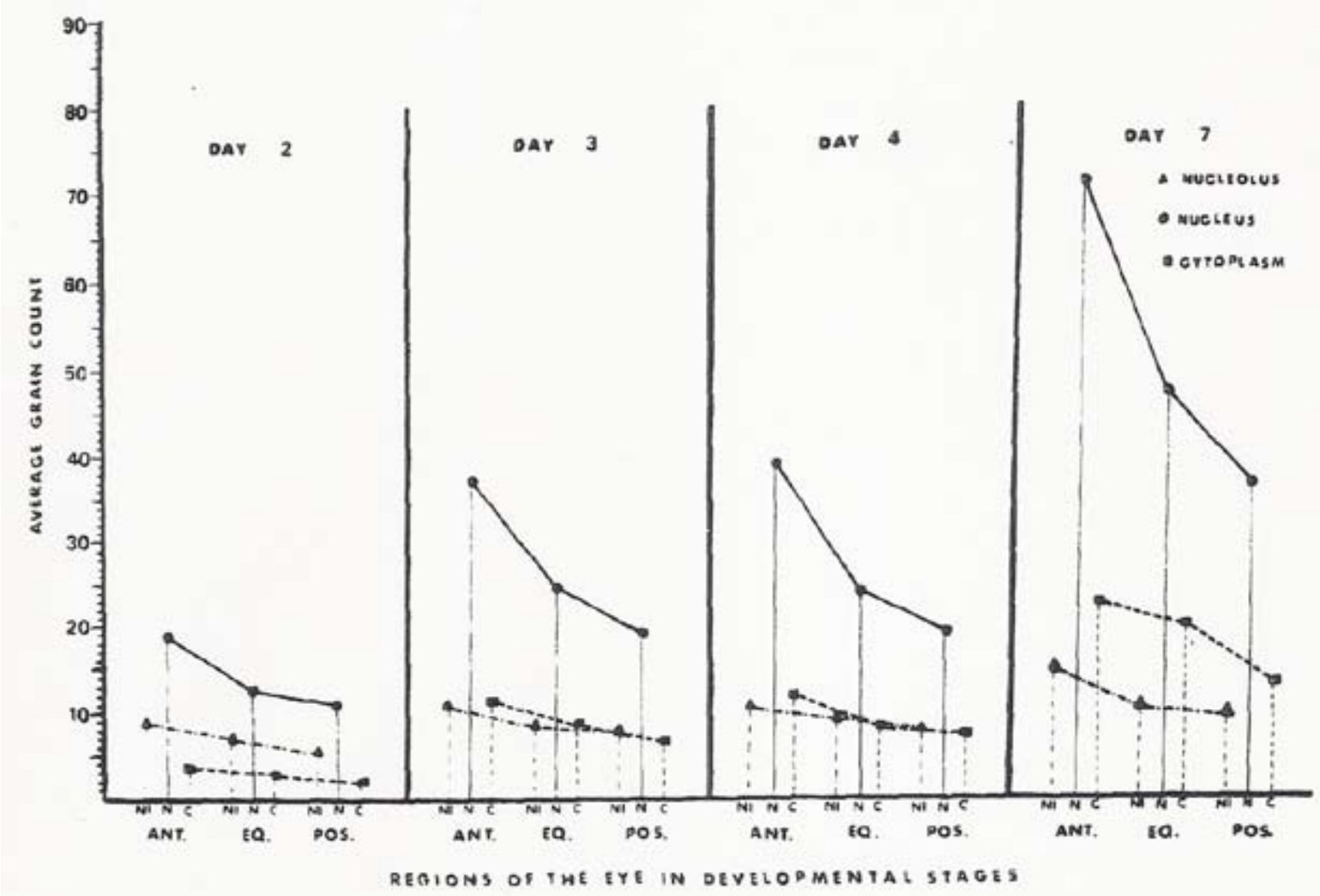

Figura 16. Transitional curves showing the average grain counts in respective 3 different cell compartments (nucleolus, nucleus, cytoplasm) of 3 retinal regions (anterior, equatorial, posterior) of chick embryo retinas labeled with ${ }^{3} \mathrm{H}-$ uridine for $1 \mathrm{hr}$ in vitro on day 2, 3, 4 and 7 during embryonal developmental stages. From Gunarso et al. (1996).

cilliary bodies at 30 minutes. These results demonstrated that this drug penetrated the conjunctiva and cornea and accumulated into the cilliary bodies (Tsukahara et al., 1980).

Befunolol is a beta-blocking agent synthesized by Kaken Co., Tokyo, Japan. Its chemical structure is 2-acetyl-7(2-hydroxy-3-isopropylamino-propoxy) benzofuran hydrochloride, which was labeled with ${ }^{3} \mathrm{H}$ and used for LM and EMRAG (Yamabayashi et al., 1981; Nagata \& Yamabayashi, 1983). The ocular tissues of chickens were taken out, cut into small pieces and labeled with ${ }^{3} \mathrm{H}$-befunolol in Eagle's MEM (3.7 MBq/ml) in a $\mathrm{CO}_{2}$ incubator for 30 to $60 \mathrm{~min}$. The tissues were cryo-fixed in liquid nitrogen and some of them were dry-sectioned, some were freeze-dried or freeze-substituted and embedded in Epon, dry-sectioned and dry-mounted. Some other tissues were chemically fixed, embedded and wet-mounted. Dry-mounting EM radioautograms revealed that many silver grains were found over the melanosomes of the pigmented cells demonstrating soluble compounds. On the contrary, only few silver grains were found over the melonosomes of the pigmented cells of the iris and the cilliary bodies by conventional wet-mounting EMRAG. From the results, it was found that soluble ${ }^{3} \mathrm{H}$-befunolol was accumulated specifically over the melanosomes of the pigmented cells, but not in the retina proper (Nagata \& Yamabayashi, 1983; Nagata et al., 1987; Yamabayashi et al., 1981)

\subsection{The refractive components of the eyeball}

The refractive media of the eyeball are the aqueous humor in the anterior and posterior chambers, the lens and the vitreous body. When we studied the ocular tissues of either chicken embryos or prenatal and postnatal aging mice, we could only fix the tissues and cells but not the aqueous humors or vitreous body. There are not so many cellular components in these media and they could not be observed morphologically by light and electron microscopy. We could find only the lens tissues in both chicken and mice. With regards to the incorporations of ${ }^{3} \mathrm{H}$-thymidine, uridine, and leucine, we observed some labels in the lens capsule, lens epithelial cells and lens fibers in chicken embryos as well as at prenatal and postnatal mice. However, because we were much interested in the 3 layers of the eyeballs especially the retina, the labeling in the lens tissues were not analyzed in details. It further requires to be studied in the future. 


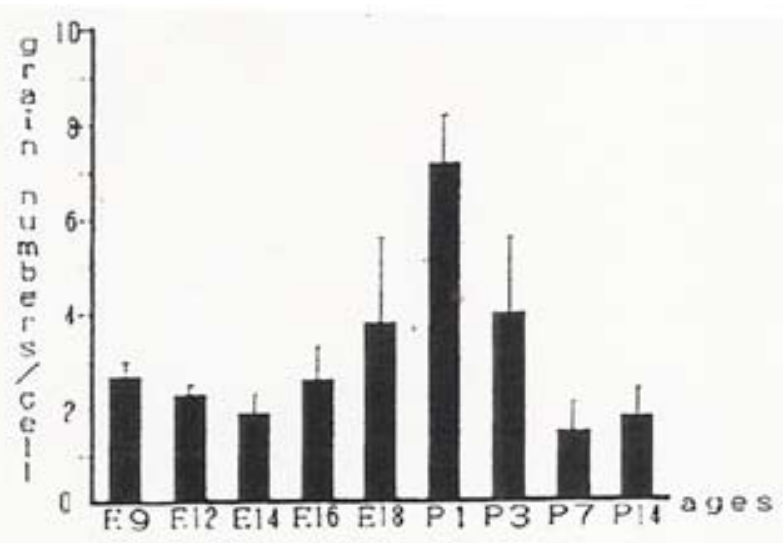

A

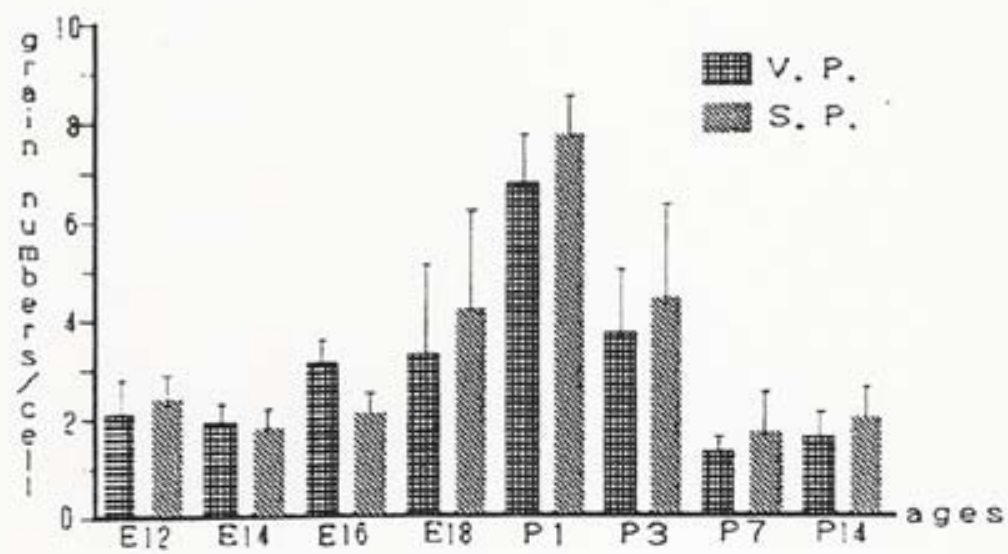

$\mathrm{B}$
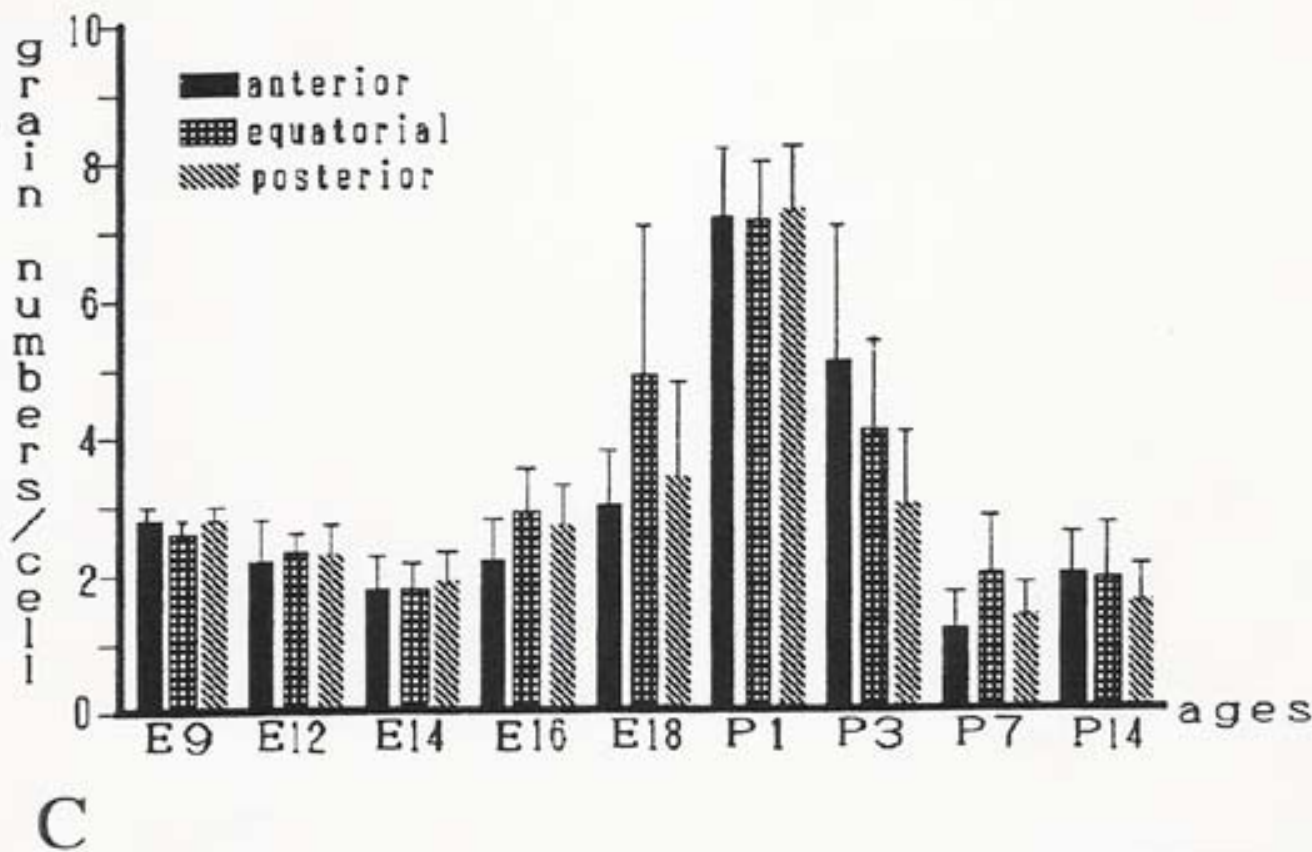

Figura 17. Histograms showing the average grain counts in the neural retinas (A), in the 2 portions of the retinas, vitreal portion (V.P.) and scleral portion (S.P.), and the 3 regions (anterior, equatorial, posterior) of mouse retina at various ages labeled with ${ }^{3} \mathrm{H}$-uridine for $1 \mathrm{hr}$ in vitro at various ages from embryonic day 9.5 to postnatal day 14 during developmental stages. From Kong et al. (1992b). 


\section{Concluding Remarks}

The methods we have developed in our laboratory to demonstrate both soluble and insoluble radioactive compounds by either wet-mounting or dry-mounting procedures at both light and electron microscopic levels and to quantify macromolecular synthesis or small molecular compounds, preparing many radioautograms at once, were briefly described.

The results from these methods applied to macromolecular syntheses, DNA, RNA, proteins, glucides and lipids in various organs, as well as the results from dry-mounting procedure demonstrating small molecular compounds such as hormones, inorganic substances, drugs in various organ systems were summarized and reviewed in connection with the aging of animals and men.

The results obtained in the present study include not only 3-dimensional structures of the organs but also the 4-dimensional features taking the time dimension into account by labeling cells and localizing the sites of incorporation, synthesis, discharge of the labeled compounds in connection with the time lapse and aging of animals. The technologies which were developed recently and the results obtained from the applications to various organs should be systematized as a new filed of science designated as radioautography of the organs.

From the results obtained, it is demonstrated that these radioactive precursors were incorporated into various cell types in various organs at various aging groups from perinatal to juvenile, mature and senescent stages showing organ specific patterns of macromolecular synthesis. It is concluded that these aging changes could answer to some questions on the biology of aging how do we get old but not why do we get old.

\section{Acknowledgments}

The author thanks Dr. Kiyokazu Kametani, Department of Instrumental Analysis, Research Center for Human and Environmental Sciences, Shinshu University, for his technical assistance during the course of this study. This study was supported in part by a grants-in-aid for scientific research, from the Ministry of Education, Science and Culture of Japan Government and a grant for promotion of characteristic research and education from the Japan Foundation for Promotion of Private Schools.

\section{References}

Appleton TC. Autoradiography of soluble labeled compounds. J Roy Micro Soc 1964;83:277-81. Christensen AK. Frozen thin sections of fresh tissue for electron microscopy, with a description of pancreas and liver. J Cell Biol 1971;51:772-804.

Cui $\mathrm{H}$, Gao F, Nagata T. Light microscopic radioautographic study on protein synthesis in perinatal mouse cornea. Acta Histochem Cytochem 2000;33:33-7

Gao F, Li S, Duan H, Ma H, Nagata T. Electron microscopic radioautography on the DNA synthesis of prenatal and postnatal mice retina after labeled thymidine injection. J Clin Electron Micrsc. 1992a;25:721-2.

Gao F, Toriyama K, Ma H, Nagata T. Light microscopic radioautographic study on DNA synthesis in aging mice cornea. Cell Mol Biol 1993;39:435-41.

Gao F, Toriyama K, Nagata T. Light microscopic radioautographic study on the DNA synthesis of prenatal and postnatal aging mouse retina after labeled thymidine injection. Cell Mol Biol 1992b;38:661-8.

Gunarso W. Radioautographic studies on the nucleic acid synthesis of the retina of chick embryo. I. Light microscopic radioautography. Shinshu Med J 1984a;32:231-40.

Gunarso W. Radioautographic studies on the nucleic acid synthesis of the retina of chick embryo. II. Electron microscopic radioautography. Shinshu Med J 1984b;32:241-8.

Gunarso W, Gao F, Cui H, Ma H, Nagata T. A light and electron microscopic radioautographic study on RNA synthesis in the retina of chick embryo. Acta Histochem 1996;98:309-22.

Gunarso W, Gao F, Nagata T. Development and DNA synthesis in the retina of chick embryo observed by light and electron microscopic radioautography. Cell Mol Biol 1997;43:189-201.

Hamburger, V, Hamilton, MIA. series of normal stages in the development of the chick embryo. J Morphol 1951;88:49-92.

Ito M, Nagata T. Electron microscopic radioautographic studies on DNA synthesis and ultrastructure of aging mouse adrenal gland. Cell Mol Biol 1996;42:279-92.

Kong Y. Electron microscopic radioautographic study on DNA synthesis in perinatal mouse retina. Cell Mol Biol 1993;39:55-64. 
Kong Y, Nagata T. Electron microscopic radioautographic study on nucleic acid synthesis of perinatal mouse retina. Med Electron Microsc 1994;27:366-8.

Kong, Y, Usuda N, Morita T, Hanai T, Nagata T. Study on RNA synthesis in the retina and retinal pigment epithelium of mice by light microscopic radioautography. Cell Mol Biol 1992a;38:669-78.

Kong Y, Usuda N, Nagata T. Radioautographic study on DNA synthesis of the retina and retinal pigment epithelium of developing mouse embryo. Cell Mol Biol 1992b; 38: 263-72.

Nagata T. A radioautographic study of the DNA synthesis in rat liver, with special reference to binucleate cells. Med J Shinshu Univ 1962;7:17-25.

Nagata T. A radioautographic study on the RNA synthesis in the hepatic and the intestinal epithelial cells of mice after feeding with special reference to binuclearity. Med J Shinshu Univ 1966;11:49-61.

Nagata T. A radioautographic study on the protein synthesis in the hepatic and the intestinal epithelial cells of mice, with special reference to binucleate cells. Med J Shinshu Univ 1967;12:247-57.

Nagata T. Electron microscopic dry-mounting autoradiography. Proc 4th Internat Cong Histochem Cytochem Kyoto 1972;43-4.

Nagata T. Simple method for mass production of radioautographs. The Cell (Saibo, Tokyo). 1982;14 $: 40-50$.

Nagata T. Electron microscopic radioautography and analytical electron microscopy. J Clin Electron Microsc 1991;2:441-2.

Nagata T. Radiolabeling of soluble and insoluble compounds as demonstrated by light and electron microscopy. In: Wegmann R J, Wegmann M A (eds.). Recent Advances in Cellular and Molecular Biology. Vol. 6. Molecular Biology of Pyridines, DNA, Peroxisomes, Organelles and Cell Movements. Leuven, Belgium: Peeters Press, 1992;6:9-21.

Nagata T. Quantitative analysis of histochemical reactions: Image analysis of light and electron microscopic radioautograms. Acta Histochem Cytochem 1993a;26:281-91.

Nagata T. Quantitative light and electron microscopic radioautographic studies on macromolecular synthesis in several organs of prenatal and postnatal aging mice. Chinese J Histochem Cytochem 1993b;2:106-8.

Nagata T. Electron microscopic radioautography with cryo-fixation and dry-mounting procedure. Acta Histochem Cytochem1994a;27:471-89.

Nagata T. Application of electron microscopic radioautography to clinical electron microscopy. Med Electron Microsc 1994b;27:191-212.

Nagata T. Radioautography in Medicine. Matsumoto: Shinshu University Press; 1994c.

Nagata T. Light and electron microscopic radioautographic study on macromolecular synthesis in digestive organs of aging mice. Cell Mol Biol 1995a;41:21-38.

Nagata T. Three-dimensional observation of whole mount cultured cells stained with histochemical reactions by ultrahigh voltage electron microscopy. Cell Mol Biol 1995b;41:783-92.

Nagata T. Technique and application of electron microscopic radioautography. J Electron Microsc 1996a;45:258-74.

Nagata T. Techniques of light and electron microscopic radioautography. In: JSHC (ed.). Histochemistry and Cytochemistry 1996. Proc. Xth Internat Congr Histochem Cytochem Kyoto, Acta Histochem Cytochem 1996;29 (Suppl.):343-4.

Nagata T. Introductory Remarks: Radioautographology, general and special. Cell Mol Biol 1996c;42(Suppl.):11-2.

Nagata T. Techniques and applications of microscopic radioautography. Histol Histopathol 1997a; 2:1091-124.

Nagata T. Three-dimensional observation on whole mount cultured cells and thick sections stained with histochemical reactions by high voltage electron microscopy. In: Motta P. (ed.). Recent Advances in Microscopy of Cells, Tissues and Organs, Roma: Antonio Delfino Editore, 1997b;37-44.

Nagata T. Radioautographic study on collagen synthesis in the ocular tissues. J Kaken Eye Res 1997c;15:1-9.

Nagata T. Techniques of radioautography for medical and biological research. Braz J Biol Med Res 1998a; 1:185-95.

Nagata T. Radioautographology, the advocacy of a new concept. Braz J Biol Med Res 1998b; 31: 201-41.

Nagata T. Histochemistry of the ocular tissues: Application of special histochemistry to ophthalmology. J Kaken Eye Res 1998c;16:1-13.

Nagata T. Aging changes of macromolecular synthesis in various organ systems as observed by microscopic radioautography after incorporation of radiolabeled precursors. Methods Find Exp Clin Pharmacol 
1999a;21:683-706.

Nagata T. Radioautographic study on protein synthesis in mouse cornea. J Kaken Eye Res 1999b:8;8-14.

Nagata T. Special radioautographology: the eye. J Kaken Eye Res 2000;18:1-13.

Nagata T. Special cytochemistry in cell biology. In: Jeon KW (ed.). Internat Rev Cytol New York: Academic Press, 2001a; Vol. 211; Chapter 2:33-154.

Nagata T. Aging changes of macromolecular synthesis in the respiratory organs as revealed by microscopic radioautography. ARBS Annu Rev Biomed Sci 2001b;3:127-55.

Nagata T. Radioautographology, General and Special. In: Graumann W (ed.). Prog Histochem Cytochem. Jena: Urban \& Fischer, 2002a;Vol. 37 (No. 2):57-228.

Nagata T. Aging changes of macromolecular synthesis in the digestive organs of mice as revealed by microscopic radioautography and X-ray microanalysis. ARBS Annu Rev Biomed Sci 2002b;4:79-132.

Nagata T. Recent advances in cytochemical methodology in medical and biological sciences. SBPN Scientific J 2004;1: 5-20.

Nagata T. Aging changes of the urogenital organs of rodents as revealed by cytochemistry and radioautography. ARBS Annu Rev Biomed Sci 2005;7:7-67.

Nagata T, Cui H, Gao F. Radioautographic study on glycoprotein synthesis in the ocular tissues. J Kaken Eye Res 1995;13:11-8.

Nagata T, Gao F, Jin C, Toriyama K. Radioautographic studies on DNA synthesis in the corneal tissues of mice. J. Kakan Eye Res 1993;1:21-8.

Nagata T, Ito M, Liang Y. Study on the effects of aging on macromolecular synthesis in mouse steroid secreting cells using microscopic radioautography. Methods Find Exp Clin Pharmacol 2000;22:5-18.

Nagata T, Kong Y. Distribution and localization of TGF $\beta 1$ and $\beta F G F$, and their mRNAs in aging mouse eye. Bull Nagano Women's Junior College 1998;6:87-105.

Nagata T, Kong Y, Usuda N. Radioautographic studies on DNA synthesis in the ocular tissues of the fetal mice. J. Kaken Eye Res 1990;8:1-28.

Nagata T, Kong Y, Usuda N. Radioautographic studies on RNA synthesis in the ocular tissues of the fetal mice. J. Kaken Eye Res 1991;9:5-13.

Nagata T, Kong Y, Usuda N. Radioautographic studies on RNA synthesis in the ocular tissues of aging mice. J. Kaken Eye Res 1992;10:1-8.

Nagata T, Ma H. Electron microscopic radioautographic study on mitochondrial DNA synthesis in hepatocytes of aging mouse. Ann Microsc 2005a;5:4-18.

Nagata $\mathrm{T} \& \mathrm{Ma} \mathrm{H}$. Electron microscopic radioautographic study on RNA synthesis in hepatocyte mitochondria of aging mouse. Microsc Res Tech 2005b; 67: 55-64.

Nagata T, Murata F. Electron microscopic dry-mounting radioautography for diffusible compounds by means of ultracryotomy. Histochemistry 1977;54:75-82.

Nagata T, Nawa T. A modification of dry-mounting technique for radioautography of water-soluble compounds. Histochemie 1966;7: 370-1.

Nagata T, Nawa T, Yokota S. A new technique for electron microscopic dry-mounting radioautography of soluble compounds. Histochemie 1969;18:241-9.

Nagata T, Shibata S, Nawa T. Simplified methods for mass production of radioautographs. Acta Anat Nippon 1967;42:162-6.

Nagata T, Toriyama K, Kong Y, Jin C, Gao F. Radioautographic study on DNA synthesis in the ciliary bodies of aging mice. J Kaken Eye Res 1994;12:1-11.

Nagata T, Usuda N, Maruyama M, Ma H. Intracellular localization of $\beta$-blockers in the ocular tissues as demonstrated by electron microscopic radioautography. Kaken Eye Res 1988;4:1-8.

Nagata T, Yamabayashi S. Intracellular localization of ${ }^{3} \mathrm{H}$-befunolol by means of electron microscopic radioautography of cryo-fixed ultrathin sections. J Clin Electron Microsc 1983;16:737-8.

Nagata T, Yamabayashi S, Usuda N, Kobayashi S. Intracellular localization of $\beta$-blockers in the cells and tissues as observed by electron microscopic radioautography. Kaken Eye Res 1987;3:1-7.

Toriyama K. Study on the aging changes of DNA and protein synthesis of bipolar and photo-receptor cells of mouse retina by light and electron microscopic radioautography. Cell Mol Biol 1995;41:593-601.

Tsukahara S, Yoshida K, Nagata T. A radioautographic study on the incorporation of ${ }^{14} \mathrm{C}$-bupranolol (beta-blocking agent) into the rabbit eye. Histochemistry 1980;68:237-44.

Yamabayashi S, Gunarso W, Tsukahara S, Nagata T. Incorporation of ${ }^{3} \mathrm{H}$-befunolol (beta-blocking agent) into melanin granules of ocular tissues in the pigmented rabbits. I. Light microscopic radioautography. Histochemistry 1981;73:371-5. 